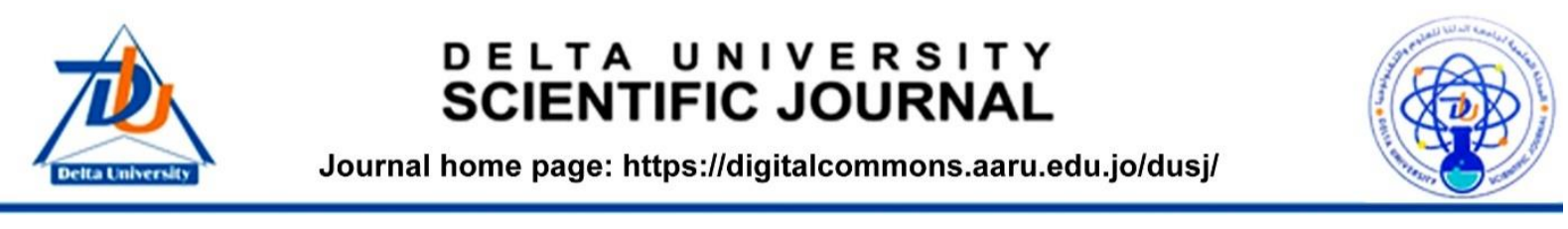

\title{
The economic impact of the Corona pandemic crisis on the Egyptian trade balance imbalance
}

\section{Mahmoud Ahmed Fawaz, ${ }^{* 1}$}

1 Faculty of Administration, Delta University for Science and Technology, mahmoud.fawaz@deltauniv.edu.eg.

\section{Keywords:}

1 - the repercussions of the Corona pandemic

2- the balance of trade

3- international trade

4- the movement of exports

5- imports

\begin{abstract}
This research aims at paying attention to the impact of global crises, including the Corona pandemic crisis, on the movement of the trade balance and to stop the incentive measures that are taken to absorb the negative economic impacts of these crises. The topics of this research dealt with showing the most important factors affecting the trade balance and its economic effects, and showing the developments in the values of exports and imports for the period 2007 to 2020 in order to determine the course of the trade balance in that period while determining the repercussions of the Corona pandemic on the movement of exports and imports during the crisis period, then proceeds to clarify the most important measures Incentive and structural reforms for the Egyptian foreign trade sector. The most important results concluded that there is a positive impact of the repercussions of the Corona pandemic crisis on reducing the trade balance deficit in the short term.
\end{abstract}

\section{التأثير الاقتصادى لأزمة جائحة كورونا على اختلالات الميزان التجارى المصرى}

$$
11
$$

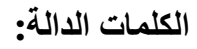

$$
\begin{aligned}
& \text { - } 1 \text { تداعيات جائحة } \\
& \text { كورونا } \\
& \text {-2 الميز ان التجارى } \\
& \text { 3-3التجارة الدولية } \\
& \text {-4حركة الصادر ات } \\
& \text { و الو اردات }
\end{aligned}
$$

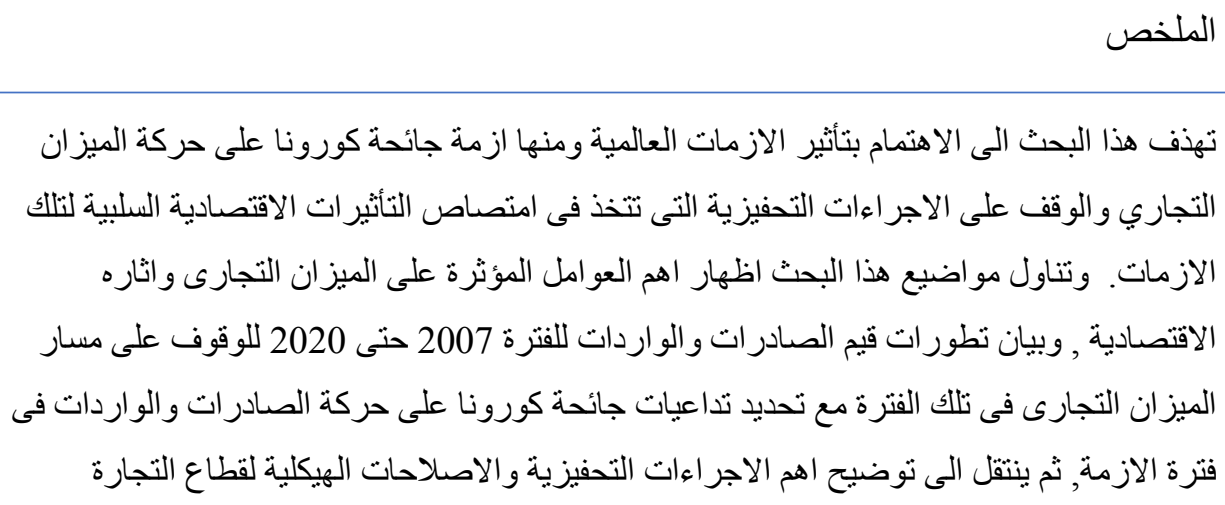


الخارجية المصري .وقد توصلت اهم النتائج إلى أن هنالك تأثير ايجابي لتداعيات ازمة جائحة كورونا على تخفيض عجز الميزان التجاري في الأجل القصير.

الازمات المصرية السابقة مع مؤشرات ازمة جائحة كورونا

المقدمة

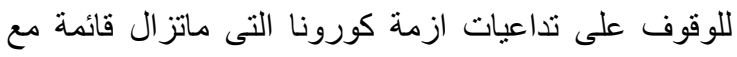
توضيح مقترحات الاجراءات التحفيزية لتفادى الاثار السلبية على قطاع التجارة الخارجية من ناحية الصادر ات والواردات , الاقتصاد بكافة قطاعاته وبصفة خاصة فى القطاع الانتاجى

و التصديرى للحد من اى ازمات اخرى مستقبلا

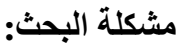

يمثل الميزان التجارى للاولة احد الاركان الاساسية لميزان

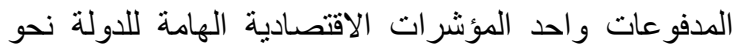

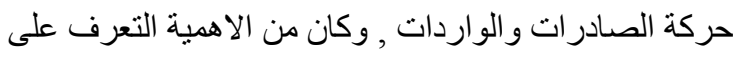

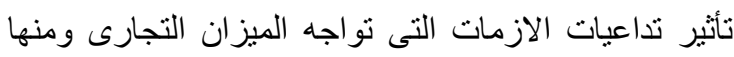

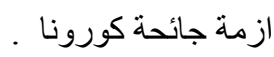
لذلك تم طرح اشكالية البحث فى سؤ الين و هما : ـ ماهو التأثير الاقتصادى لأزمة جائحة كورونا على اختلال

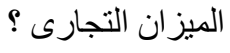

- وما هو تأثثير الآليات المعالجة لتداعيات الازمات الاقتصادية

لامنصاص اختلال الميزان التجاري؟

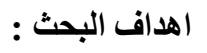

ـ الاهتمام بدراسة تأثير الازمات الاقتصادية المصرية ومنها تداعيات ازمة كورونا على حركة الصادرات والواردات بالميزان التجاري لتداركها فى ازمات اخرى مستقبلية. ـ معرفة اثر معالجة العجز المزمن للميزان التجارى في ظل الاجر اءات التحفيزية لتنتيط القطاعات الانتاجية للاولة

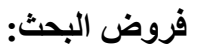

ـ اثرت تداعيات جائحة كورونا تأثير سلبى فى زيادة الصادر ات

- اثرت تداعيات جائحة كورونا نأثير ايجابى فى خف

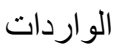

ـ اثرت تداعيات ازمة كورونا على خفض عجز الميزان

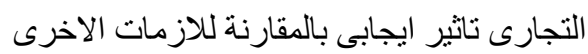

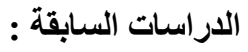

تعتبر التجارة الخارجية أحد الداخل الأساسية في التتمية

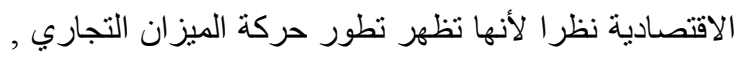

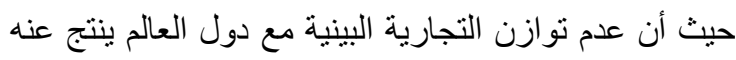
عجز مستمر ومتز ايد في ميزان المدفوعات يؤدي إلي اختلال

البنيان الاقتصادي. وتعد أزمة كورونا من احدى الازمات الثديدة على مدار التاريخ الانسانى والتى أدت الي حدوث انخفاض فى حركة الته التجارة الدولية وركود علي المستوي العالمي , مما اثرت علي

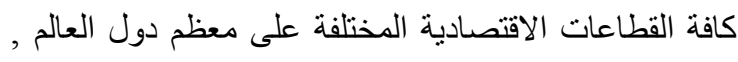
ونتيجة لهذا الوباء و التذاعيات التي تتخذها اي دولة لمواجهة فيروس كورونا تم اغلاق العديد من القطاعات الاقتصادية

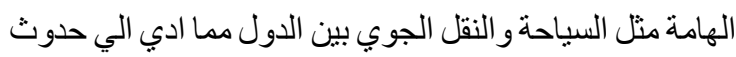

$$
\text { الركود الاقتصادي علي المستوي العالمي . }
$$

وكانت مصر من ضمن الدول التي ناثرت بهذا الوباء , ومن بين الدول ايضا التي طلبت المساعدة من صندوق النقد الدولي

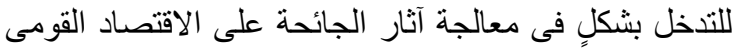

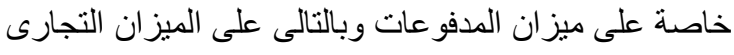

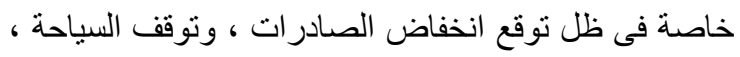
وضعف تحويلات العاملين في الخارج و من المرجح أن يؤدي أني ارتفاع معدلات المخاطر العالمية إلى الحد من التدفقات المالية

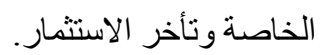
لذلك تبذل مصر العديد من الاجراءات اللازمة لاحتواء

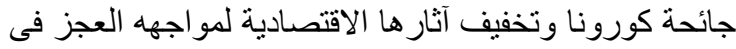
الميزان التجارى وفجوة ميز ان المدفو عات , بالاضافة الى بحث الطرق التي تجعل الاقتصاد المصري يعيش الأزمة بأقل قدر

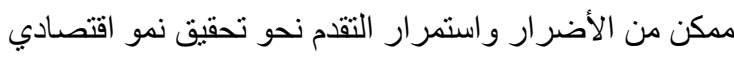
وفى هذه البحث نوضح تناثير الازمات المصرية التى شاهدها الاقتصاد المصرى خلال الفتره منذ الازمة المالية العالمية منذ عام 2007 وما بعدها من ازمات واحداث محلية داخل مصر حتى عام 2020، وتاثير تلك الازمات على الميزان التجارى المصرى مع رصد حركة الصادر ات والواردات فى الفتره ما قبل الازمة وبعدها, ورصد ومقارنة مؤشرات هذه 


$$
\text { - در اسة (مريم كثنك) } 2017
$$

يتناول هذا البحث الأثر الذي يمكن أن بتركه تخفيض قيمة

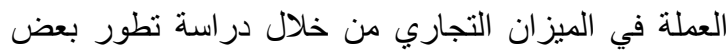
متغير ات الاقتصاد المصري ، و علي وجه خاص تطور أسعار الصرف ونطور حجم الصادر ات و الواردات في مصر، وتوصلت الدراسة إلى أن هناك تأثثير ايجابي على الثى الميزان التجاري في الأجل القصير.

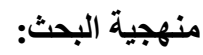

يعتمد البحث على المنهج التحليلي الوصفي في بيان طبيعة

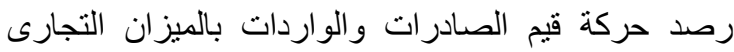
المصرى خلال فترة ما قبل الازمات المصرية وما بعدها للوصول الدقارتة بالأثر الاقتصادى لتداعيات ازمة كورونا

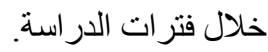

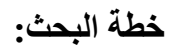

ينقسم البحث إلى اربعة محاور رئيسية: المحور الاول : العوامل المؤثرة على الميزان التجاري و اثاره

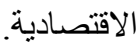

الدحور الثانى : الازمات المصرية المعاصرة واثرها على

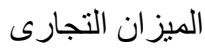

المحور الثالث : تداعيات نأثثر جائحة كورونا على الميزان

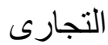

المحور الرابع : الاجر اءات التحفيزية والاصلاحات الهيكلية

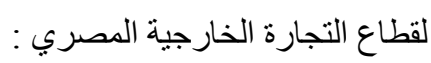
المحور الاول : العوامل المؤثرة على الميزان التجاري

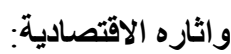

من المعروف ان الميزان التجارى هو حساب من حسابات ميزان المدفوعات و يقصد به رصيد العطليات التجارية بمعنى الفرق بين قيم الصادرات وقيم الواردات من السلع و الخدمات خلال فترة معينة. وتكمن القيمة الاقتصادية للميزان التجارى في تحليل مكوناته وليس في قيمته المطلقة، لهذا لابد من معرفة نو عية

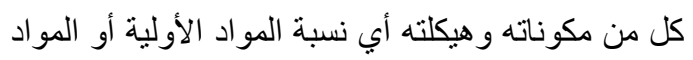

لاتوجد دراسات سابقة للتأثثرات الاقتصادية لتداعيات تلك الجائحة العالمية التى لم يسبق ان تأثر بها العالم من قبل, ولكن توجد در اسات لازمات مالية عالمية متثابهه مثل الازمة المالية

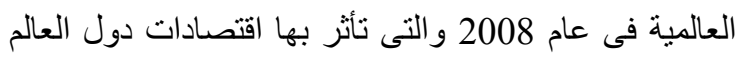
وهى الاقرب لهذا البحث , واخرى عن تأثيرات الميزان التجارى .. ومنها بعض الدر اسات الاتية:

$$
\text { - 2010 در اسة (سلوى صسابر ) - }
$$

تناولت هذه الدراسة الازمات العالمية ونأثير ها على الاقتصاد

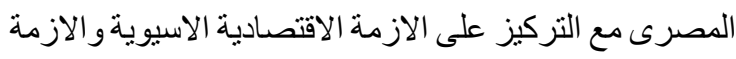

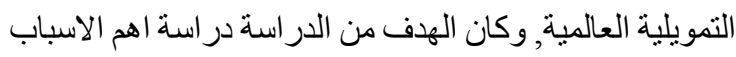

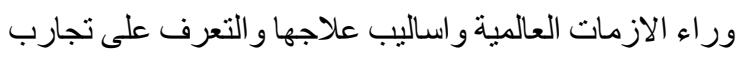
بعض الدول وتقييم اثر الازمة الاقتصادية الاسيوية والازمة

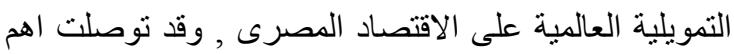

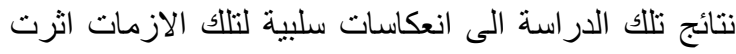

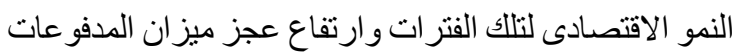

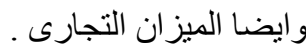

\section{) 2010 The study (Hussein Elasrag}

This study dealt with the global financial crisis in 2008 and its impact on the Egyptian This study aims to, economy in a way analyze the global financial crisis in 2008 and its impact on the Egyptian economy to deal with future crises, and the results reached negative effects on the Egyptian economy and export

$$
\text { - 2017 - در اسة (سامح محجوب) }
$$

تناولت هذه الدراسة اثر الازمة العالمية على الميزان

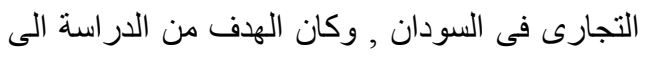
إلقاء الضوء على الأزمة المالية العالمية 2007-2008 وأثرها على الميزان التجاري في السودان, وقد تم التوصل إلى عدد من النتائج أهمها : تأثر الميزان التجاري السوداني بالازمة المالية العالمية التي حدثت

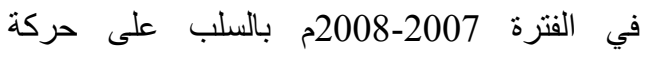
الصادر ات وبالايجاب على حركة الو اردات. 
يجب أن تكون عليها فسيؤدي ذلك إلى توسع الصادر ات مقابل تقلص الواردات , لذلك تغير سعر صرف العملة المحلية امام العملات الاجنبية يؤدي إلى حدوث تغير حركة الصادرات و الواردات في الميز ان التجاري.(2) 3. التغير في معدلات اسعار الفائدة :

ترتبط تغيرات أسعار الصرف بمعدلات الفائدة بين

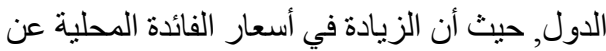
باقى الدول الخارجية سوف تجذب رؤوس الأموال

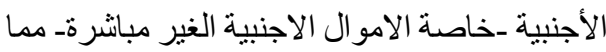
يؤدي إلى ارتفاع قيمة العملة المحلية في سوق

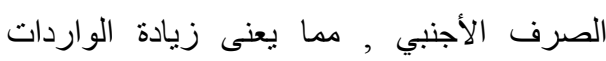
وانخفاض نسبى للصادرات فى حركة الميزان

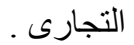
أما انخفاض أسعار الفائدة في الداخل عن باقى دول العالم فيؤدى ذلك الى هروب رؤوس الامو ال الاجنبية للخارج , مما يؤدى الى انخفاض قيمة العملة المحلية فى سوق الصرف الاجنبى, مما بعنى ذلك زيادة الطلب لئل

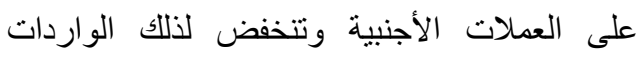
و ارتفاع نسب للصادر ات فى حركة الميزان التجارى.

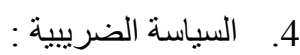

إن الاجراءات الضريبية المختلفة التي تفرضها الدولة قد تغير في مستويات دخول الافراد, فاذا انخفضت الضرائب فان ذللك يرفع الدخول ويؤدي إلى زيادة الطلب المحلى على السلع و الخدمات بشكل عام، ومن هذه السلع و الخدمات ما هو مستورد من الخارج، و هذا

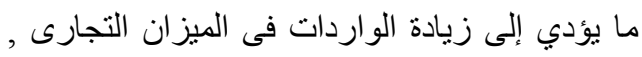

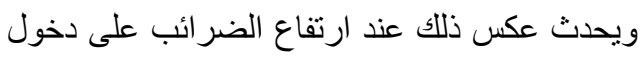

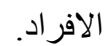
ويتأثر الميزان التجارى ايضا بضرائب الارباح التجارية والصناعية داخل الدولة كتكاليف الانتاج. 5. الاتفاقيات التجارية بين دول العالم: (3)

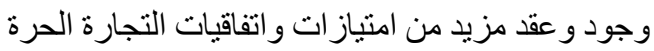
و العلاقات التجارية المتميزة بين بعض دول العالم يمكن استغلالها في تحقيق نوفير فرص نمو الصادرات وتتجيع نفاذية المنتجات و السلع المصرية إلي الاسو اق العالمية , حيث نوجد فى التجارة الدولية القيود الجمركية متعددة الأطر اف أو الثنائية أو الأحادية على لئى
نصف المصنعة أو المصنعة إلى اجمالي المستوردات أو

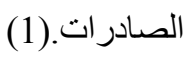
و لا ينبغي بالضرورة أن ينظر إلى هذا العجز بنظرة سلبية بل كحدث دوري منصل بالدورة الاقتصادية، الدول ذات الاقتصاد المتنامي مثل الولايات المتحدة الأمريكية و انجلترا و واستر اليا لديهماعجز تجاري، لكن هذه الدول لديها القدرة لمواجهه الطلب المحلى الضخم فى فنرات التوسع الاقتصادى.

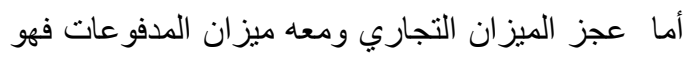

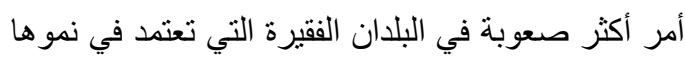
و اقتصادها على الاستثمار الاجنبى. العوامل المؤثرة على حركة الميزان التجارى الأبى تتثمل العو امل التى تؤثر على الميزان التجارى عدة عو امل تختلف من دولة لاخرى طبقا للعوامل الاقتصادية و السياسية والاجتماعية فى كل دوة , ومن اهم العوامل المؤثرة على حركة الميز ان التجارى ما يأتى :

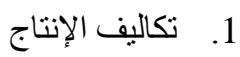

تشمل تكاليف الانتاج من الارض و العمال ورأس

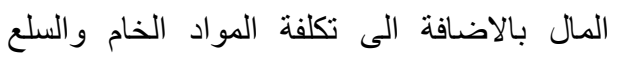
الوسيطة و المدخلات الأخرى ومدى نوفر ها, وتتمل ايضا تكاليف الانتاج جميع انو اع الضر ائب التجارية وخصم حوافز الدعم. وتتباين تكاليف الانتاج في اقتصاد الدولة المصدرة

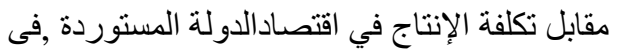

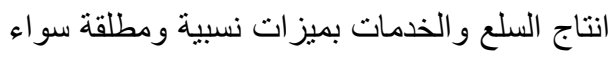
فى الاسعار او جودة الانتاح , لذا قامت التجارة

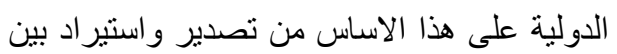

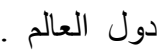

$$
\begin{aligned}
& \text { 2. تغير اسعار صرف العملات : }
\end{aligned}
$$

توجد علاقة وثيقة بين الميز ان التجاري وسعر صرف

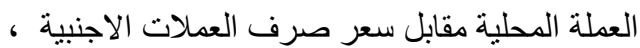
فإذا كان سعر الصرف العملة المحلية أكبر من قيمتها الحقيقية سيؤدي ذلك إلى ارتفاع أسعار سعر السلع

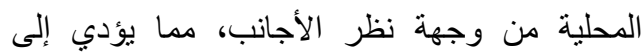
انخفاض الطلب الخارجي عليها ، وبالتالي سيؤدي ذلك الكي إلى حدوث اختلال في الميزان التجاري.

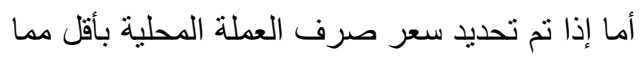


الفائض حصول البلا المعني على عملة أجنبية يضيفها إلى احتياطياته من هذه العملة لضمان تمويل مستورداته وتسديد

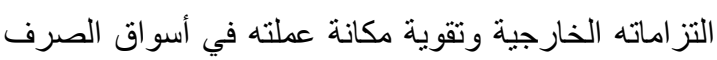
الدولية و المحافظة على قيمتها الثر ائبة، كما يعني تثغيل اليد اليد الثناف العاملة التي لو لا القدرة على التصدير لما أمكن تشغيلها، كما

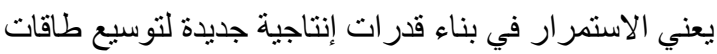
البلا في تلبية حاجاته وزيادة صادر اته . 2. العجز في الميزان التجاري إن العجز في الميزان التجاري يكثف عن مو اطن الضعف في انجاري اقتصاد البلا الذي يعانيه، ويعبر عن قصور الطاقات الإنتاجية

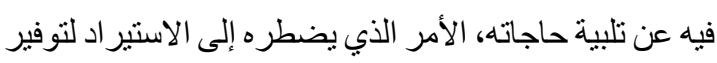

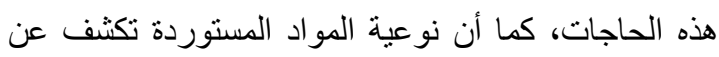

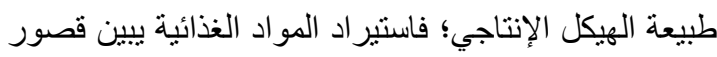

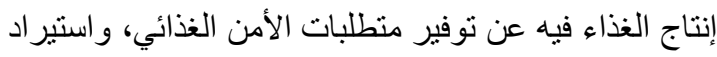
الآلات والتجهيزات يكثف عن قصور صناعة الآلات و التجهيزات فيه، كما أن العجز المستمر في الميزان التجاري

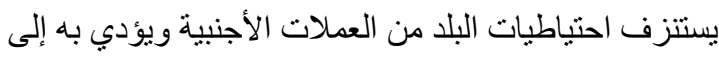

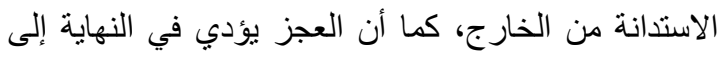

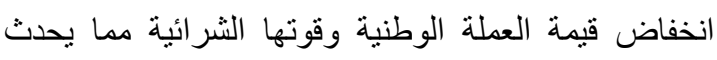

$$
\text { أزمات اقتصادية واجنماعية غير مستحبة . }
$$

و إنه لبس بالضرورة أن يكون الفائض أو العجز التجاري

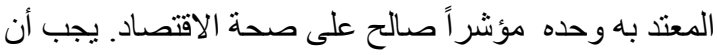

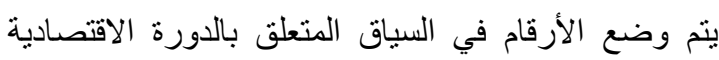
و المؤشرات الاقتصادية الأخرى في الاعتبار كما ويؤثر تعريف الميزان التجاري على الناتج الدحلي الإئي الإجمالي للاولة، إذ ينأثر الناتج المحلي الإجمالي بهذا الميزان

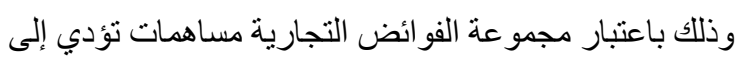

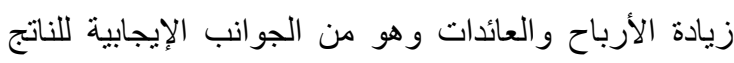

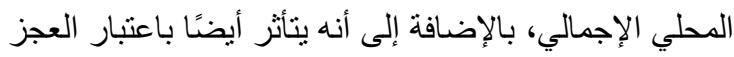

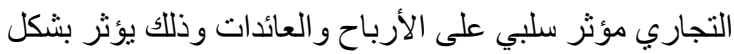
سلبي على مجموع الناتج المحلي الإجمالي، لذلك فإن الناتج

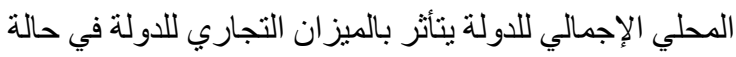

العجز التجاري والاقتصادي أو الفائض التجاري. (4).

المحور الثانى الازمات المصرية المعاصرة واثرها على

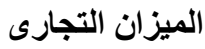

التجارة الدولية بين بلدين أو القيود غير الجمركية مثل

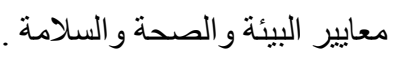

وعقدت مصر العديد من اتفاقيات التبادل التجاري والتسهيلات الجمركية كمناطق حرة تفضيلية بين مجموعة بعض الدول لتعزيز جانب الصادرات فى الميز ان التجارى, مثل اتفاقيات دول الكوميسا بين دول لنال شرق وجنوب افريقيا , و اتفاقية الثراكة الصصرية والاتحاد الاوربى , واتفاقية التجارة الحرة للاول ولئل العربية, و اتفاقية الميركسور لدول امريكا الجنو بية .

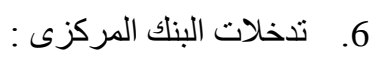

تحدث هذه التنخلات عندما يحاول البنك المركزى لبلد ما لتعديل سعر الصرف العملة عندما لايكون مناسبا لسياسه النقدية وللظروف المالية والاقتصادية للدولة

$$
\text { و هو مايعرف "بسعر الصرف المدار. " }
$$

ففي حال حدوث اختلال في الميزان التجارى او ميزان

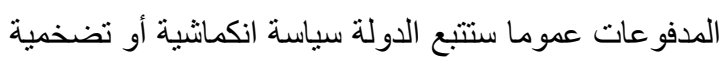
لإعادة التوازن عن طريق التخفيض أو الرفع في سعر العملة،

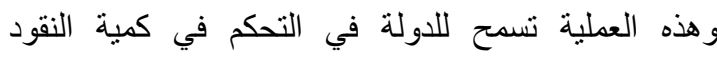

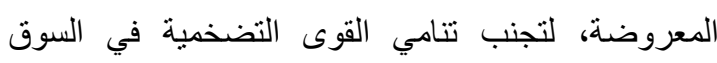

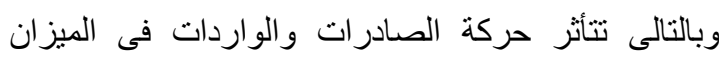
التجارى طبقا لسياسة الدولة التوسعية و الانكماثية . الاثر الاقتصادى لحركة الميزان التجارى

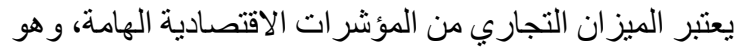

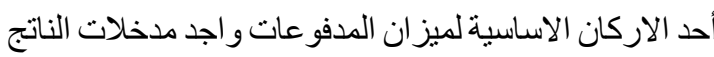

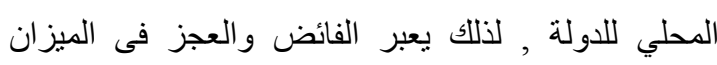
التجارى عن مؤشر القوة الاقتصادية والضعف في اقتصاد

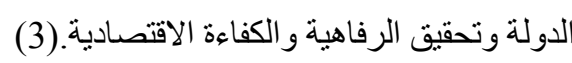
1 الفائض في الميزان التجاري على الرغم من أن الميزان التجاري ليس إلا جزءً من ميزان المئري

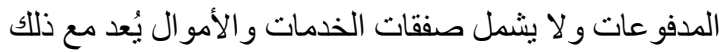
ذا دلالة كبيرة في رصيده الإيجابي والسلبي فالفائض في الميزان التجاري يعبر عن عوامل صحية في الاقتصاد المعني، فهو يثير أولاً إلى الطاقة الإنتاجية الو اسعة والفائضة

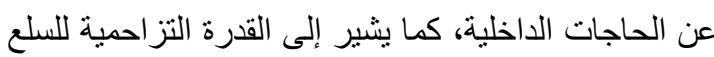

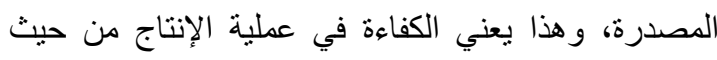
التكلفة والجودة و التلاؤم مع الأذواق في الأسو اق الخارجية،

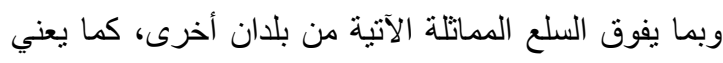


ومن ناحية اخرى قامت عدد من البنوك المركزية الأخرى في مختلف أنحاء العالم بتخفيض أسعار الفائدة، بهدف تنتجيع

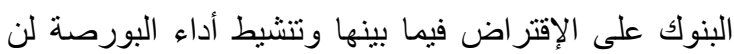

$$
\text { تكون كافية للخروج من الأزمة. }
$$

ولم تكن مصر بعيدة عن تأثيرات الازمة المالية العالمية وتفاعلاتها ، بحكم اعتمادها على اقتصاد السوق وما ينطوى عليه من تثابكات عالمية، وتأثرت بذلك القطاعات الاقتصادية التى تعتمد على السياحة كمدر للاستثمار و الدخل و انخفاض

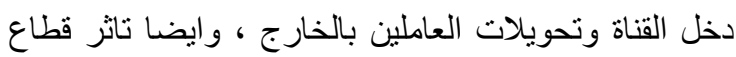
التجارة الخارجية.من صادرات وواردات .

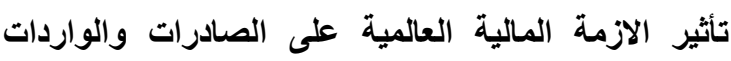

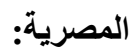

تأثرت الصادر ات و الواردات المصرية بالازمة المالية العالمية ومن ثم تأثر ميزان التجارى وميزان المدفوعات، وقد حاولنا

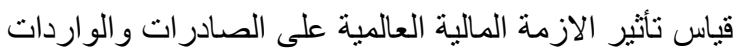
ومن ثم الميزان التجارى الدصرى وقياس نسب الزيادة

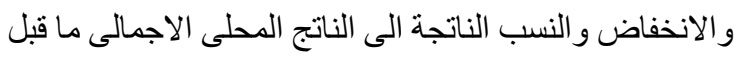

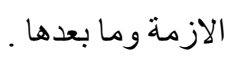

التأثير على الصادرات ما قبل وبعد الازمة المالية

يتضح من الثكل رقم (1 ) ان قيمة الصادرات المصرية فى السنة المالية 2008/2007 قبل الازمة المالية العالمية بلغت 29355.8 مليار دو لار ، وكانت صادر ات الربع الاول من تلك التك السنة المالية 5989.8 مليون دو لار, و الربع الثانى 7113.3

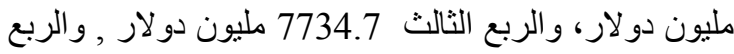

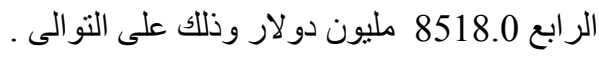

بينما بلغت قيمة الصادرات فى السنة المالية 2009/2008 وذلك اثثاء الازمة المالية العالمية , حيث بلغت 29355.8 مليار دو لار , وكانت صادرات الربع الاول من تلاك السنة المالية 8162.9 مليون دو لار, و الربع الثانى 5433.4 مليون دو لار, و الربع الثالث 5657.8 مليون دو لار , و الربع الر ابع 5914.8

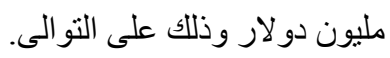

ومن خلال الجدول (3،2) لتحليل الصادرات المصرية قبل الازمة وبعد الازمة يتبين هناك انخفاض فى صادرات السنة المالية 2009/2008 وهى السنة المالية للازمة المالية بمقدار 14.26\% عن السنة المالية 2008/2007 , ونلاحظ انخفاض
ناثر الاقتصاد المصري بالعديد من الازمات والاحداث و الاختلالات الاقتصادية بداية من ناثير الازمة المالية العالمبة

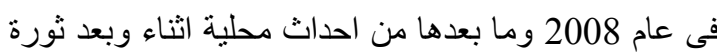
2011 ، ثم واجه خلالها ضغوطاً متتامية جراء بطء النمو الاقتصادي وارتفاع مستويات البطالة بسبب نقص الاستثمار

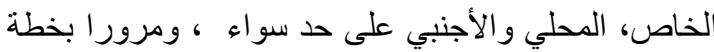
الاصلاح الاقتصادى لصندوق النقد الدولى فى عام 2016 , حنى اتت صدمة تعويم سعر الصرف الاجنبى فى عام 2017 وما ادى الى انخفاض قيمة الجنية المصرى مصحوبا بارتفاع التضخم وارتفاع نسبة الفائدة , الى ان اجتاح العالم جائحة

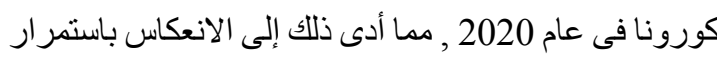
العجز في ميزان الددفوعات الدصرى وتذبذب حركة الصادرات و الو اردات فى الميزان التجارى .(5 (5)

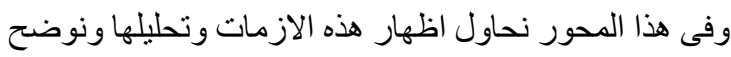
تأثير ها على الصادرات والواردات المصرية و ومؤشرات الميز ان التجارى ماقبل الازمة وبعدها الازمة المالية العالمية عام 2008 تعود بداية الأزمة المالية العالمية إلى أغسطس 2007 عبر

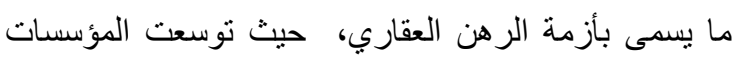

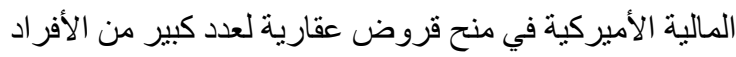

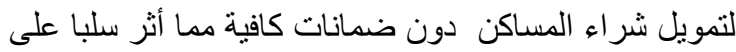
قدرنها المالية ، وأدت تبعا لذلك الى تدخل البنوك الاحتياطية

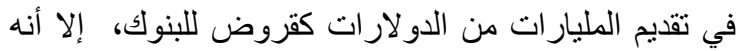

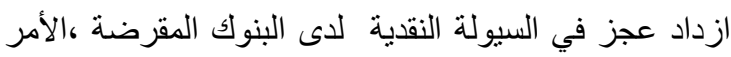

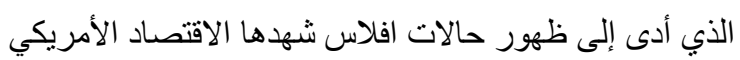

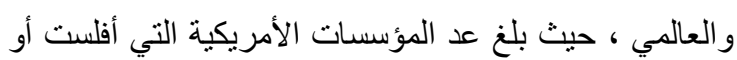

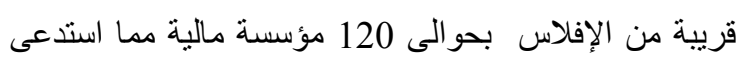

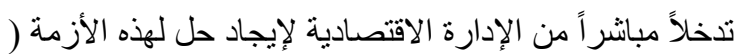

وقد امند تأثير الأزمة إلى الأسواق والمؤسسات الأساسية في

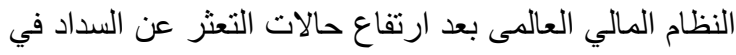
سوق الرهون العقارية ، حيث قامت البنوك ببيع الديون إلى شركات التوريق التي أصدرت بموجبها سندات قابلة للتداول

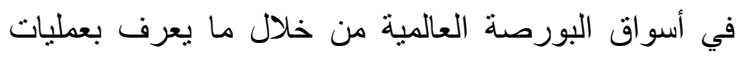
"التوريق" وتو الت عمليات التوريق و التي أدت إلى بدور ها إلى الى لئي توسع الفجوة بين الاقتصاد الحقيقي والاقتصاد المالي 
على الصادرات والواردات يذكر أن الحكومة المصرية أعدت فى حينها حزمة من البرامج

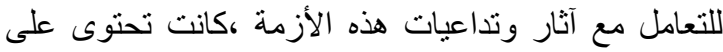

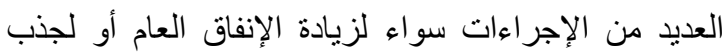

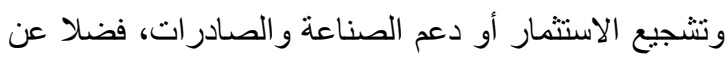

عدد من الإجر اءات المالية و النقدية من أهمها: (7) - فتح اسو اق جديدة للتصدير ، حيث تمثل الاسو اق الجديدة بديلا لمواجهه حالات الكساد والركود ،وعلى ذلك تستوجب هذه الازمة زيادة عدد اليات البحث عن اسواق بديلة وفرص تصديرية جديدة. - إجر اء تخفيضات في التعريفة الجمركية علي سلع وسيطة

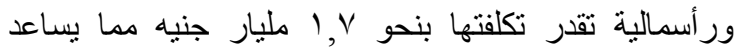
المنشآت على المنافسة فى الخارج ويشجع على الاستثمار

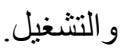
ـ تحمل تكلفة ضريبة المبيعات علي السلع الر أسمالية بحيث لا يتحملها المستثمر عن أى استثمار ينشأ فى العام القادم. ـ الاستمر ار في تحفيز وجذب الاستثمار ات من الخارج عموما ومن المنطقة العربية خصوصا وبما لا يقل على • ا مليارات

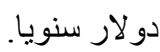
- فى مجال الزر اعة هناك مشروع لتخصيص مساحات من الأراضي فى حدود ه آلاف فدان لكل مستثر لإنثاء

$$
\text { مشرو عات تصنيع زر اعى موجهه }
$$
ـ تثبيث أسعار الطاقة للمشرو عات المتوسطة و الصغيرة حتى فئى نهاية عام 9 . . T ، بينما ستحصل عليها المشروعات الكبيرة بالأسعار العالمية تثبيت أسعار الطاقة للمشروعات المتوسطة

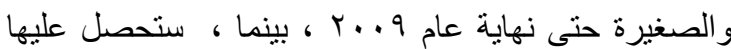
المشروعات الكبيرة بالأسعار العالمية. - توفير اعتمادات إضافية بنحو . . مليون جنيه لصندوق دعم الصادر ات الذى تستفيد منه نحو .ا ا شركة مصرية يعمل بها حو الى • •یء ألف عامل، وذللك لوضع الثركات المصرية

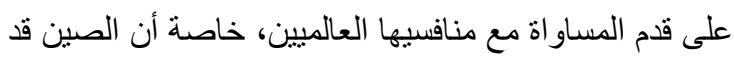

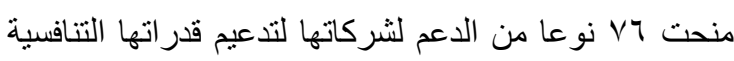

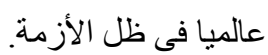
ـ تثبيت أسعار الطاقة للمشرو عات المتوسطة و الصغيرة حتى نهاية عام 9 . . r ، بينما ستحصل عليها المشروعات الكبيرة
ملحوظ للشهور الفصلية فى المقارنة بين تللك السنوات وكانت الفترة من شهر ابريل الى شهر يونيو فى عام 2009 الاكثر انخفاضا عن نفس الفصل للعام السابق بنسبة 30.6\% التأثير على الواردات ماقبل وبعد الازمة المالية : تشير جدول (1) النقيمة الواردات المصرية فى السنة المالية 2008/2007 قبل الازمة المالية العالمية بلغت 52771.2 مليار دو لار ، وكانت واردات الربع الاول من تلك السنة المالية 11190.7 مليون دولار, والربع الثانى 13181.3 مليون دو لار, و الربع الثالث 13255.6 مليون دولار , و الربع الرابع 15143.6 مليون دو لار وذللك على التو الى . بينما بلغت الو اردات فى السنة المالية 2009/2008 وذلك اثناء الازمة المالية العالمية بقيمة 50342.2 مليار دو لار ، وكانت صادرات الربع الاول من تللك السنة المالية 15162.9 مليون دولار، و الربع الثانى 13060.9 مليون دولار، و الربع الثالث 10523.6 مليون دولار ، والربع الرابع 11594.8 مليون دو لار وذلك على التو الى. ومن خلال تحليل الواردات المصرية قبل الازمة وبعد الازمة للجدول رقم $(2,3)$ يتبين هناك انخفاض فى واردات السنة المالية 2009/2008 وهى السنة المالية للازمة المالية بمقدار 4. 6\% عن السنة المالية 2008/2007 ، ونلاحظ ايضا انخفاض ملحوظ للشهور الفصلية فى المقارنة بين تلك السنوات ، وكانت الفترة من شهر ابريل الى شهر يونيو فى عام 2009 الاكثر انخفاضا عن نفس الفترة للعام السابق قبل الازمة العالمية بنسبة 23.4\% وتبعا لذلك تظهر مؤشرات الميزان التجارى فى السنة المالية قبل الازمة المالية العالمية لعام 2007 /2008 فقد زاد العجز بنسبة \%7.5 عن السنة المالية 2009/2008 اثناء الازمة وما بعدها وكان نسبة العجز فى الميزان التجارى الى اجمالى الناتج المحلى وفقا بعناصر الانفاق بالاسعار الجارية بلغت قبل الازمة 14.3\% وبلغت بعد الازمة 12.2\% ، وكانت نسبة تغير الصادرات الى الناتج المحلى المحلى ماقبل الازمة وبعدها بانخفاض 0.86\% ، و ونسبة تغير الواردات الى الناتج المحلى المحلى قبل الازمة المالية وبعدها بانخفاض 1.07\% وهذه المؤشر ات تبين انخفاض عجز الميز ان التجارى نتيجة انخفاض

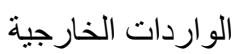

الاجراءات والحوافز التى قدمت من الحكومة لتداعيات الازمة 
تأثثير احداث 25 يناير 2011 على الصادرات والواردات المصرية:

تاثز الاقتصاد المصرى خلال احداث مابعد 25 يناير 2011

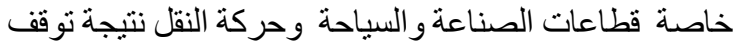
المصانع و الاضطر ابات السياسية و الأمنية في أرجاء البلاد؛

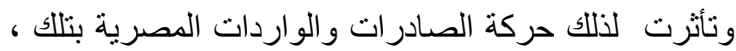
وقد حاولنا قياس تأثير تداعيات ثورة 25 يناير 2011 على ولى ولى

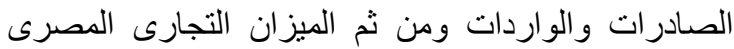
وقياس النسب الناتجة الى الناتج المحلى الاجمالى ولى التيل الجاري

التأثير على الصادرات ما قبل وبعد احداث 25 يناير 2011: يظهر جدول (1) قيمة الصادرات المصرية فى السنة المالية 2010/2009 قبل احداث 25 يناير بلغت 23873.1 مليار دولار ، وكانت صادرات الربع الاول من نللك السنة المالية 5390.3 مليون دولار, و الربع الثانى 6126.4 مليون دولار، و الربع الثالث 5450.4 مليون دولار ، و الربع الرابع 6906.0 مليون دو لار وذللك على التو الى .

بينما فى السنة المالية 2011/2010 وذللك اثناء احداث ثورة 25 يناير ، بلغت قيمة الصادرات 26992.5 مليار دولار ، وكانت صـادرات الربع الاول من تللك السنة المالية 6102.0 مليون دو لار، و الربع الثانى 6565.8 مليون دولار ، و الربع الثالث 6243.3 مليون دو لار ، و الربع الرابع 8081.4 مليون

$$
\text { دولار وذلك على التو الى. }
$$

ومن خلال تحليل الصادرات المصرية قبل احداث ثورة 25 يناير وما بعدها بالجدول رقمى (2,3)، يتبين ان هنالك زيادة فى صادر ات السنة المالية 2011/2010 وهى السنة المالية لما بعد احداث 25 يناير بمقدار 13.1\% عن السنة المالية ما قبل الاحداث 2010/2009 , ونلاحظ ارتفاع ملحوظ للشهور الفصلية قبل الاحداث فى المقارنة بين تلك السنو ات، ولكن اكبر ارتفاع كان فى الفترة من ابريل الى يونيو بعد الاستقرار النسبى للاحداث وكانت بنسبة 17\% ويرجع تلك الزيادة فى التصدير الى اتفاقيات تصدير توقفت فى الفترات السابقة لوجود الاضطر ابات ، مع ارتفاع سعر الصرف الدولار امام الجنية المصرى فى تلك الفترة من 5.446 للدولار فى عام 2010/2009 الى 5.941 للدو لار فى عام 2011/2010 ما قد
النوعية من الدعم التى كانت قاصرة على الصادرات إلى أفريقيا وبعض المناطق المحددة لتشمل مناطق أخرى يتم تحديدها وتتحمل فيها الحكومة نصف التكلفة لتنشيط لصادر ات.

\section{احداث ثورة 25 يناير 2011}

تعرض الاقتصاد فى الشهور الاولى من احداث ثورة 25 يناير 2011 إلى ضرر بالغ في جميع قطاعاته ومؤشر اته، فخسائر البورصة المصرية تخطت 72 مليار جنيه خلال الأيام الأولى منذ اندلاع الأحداث، وارتفعت خسائر قطاع النقل إلى 15 مليون جنيه يوميًا، ومنيت السكك الحديدية بخسائر يومية 4 ملايين جنيه، إضافة إلى خسائر الموانئ المصرية نحو 10 ملايين جنيه يوميًا، فضلًا عن خسائر شركات الطيران، وخسارة أخُرى بلغت 90 مليون دولار نتيجة لقطع شبكة الإنترنت خلال الأيام الأولى من الاحتجاجات الثعبية الواسعة. فيما كان تراجع مؤشرات الاقتصاد المصرى خلال الثهور التالية لـه بناير دليلً على أزمة كبيرة، لحقت بقطاعات الصناعة والسياحة نتيجة توقف المصانع و الاضطر ابات السياسية والأمنية في أرجاء البلاد؛ حيث أشارت التقارير الرسمية إلى نراجع معدلات نمو الناتج المحلى الإجمالى الحقيقى لتسجل ؟ ـ ؛ كما تر اجع مستوى الاحتياطى من النقد الأجنبى ليغطى ب أثهر فقط من الواردات، فضلً عن ارتفاع العجز المالى إلى ما يقرب من \& ا ٪ من الناتج المحلى الإجمالي، وكذلك ارتفاع معدل البطالة الرسمى إلى ؟.با ٪.

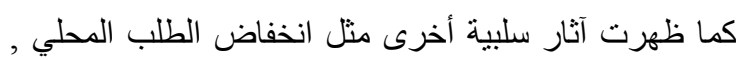
وتحديدا، تأثر الاستهلاك الخاص والاستثمار سلبا نتيجة تعطل النشاط الاقتصادي بصورة مؤقتة واستمر ار حالة عدم اليقين، وقد استمر هذا التأثير السلبي حتى عودة الاستقرار تدريجيا فى

كما أن هذا التدهور الذي شهده الاقتصاد المصري خلل تلك السنوات كان له أنعكاس كبير على الساحة المصرية ،وظهور العديد من المشاكل الاقتصادية أهمها مشكلة التضخم ،حيث بلغ معدل التضخم في عام 2014 نسبة 10 \% مقارنة فى عام 2012 الذي كان نسبة 7,5 \% ،و هذا المعدل يوضح مدى عمق المشكلة الاقتصادية التي يعاني منها الاقتصاد المصري.في مقابل ذلك أرتفاع معدل البطالة، أذ بلغ هذا المعدل في عام 


\section{صدمة تحرير سعر الصرف (تعويم الجنية المصرى)}

فى نوفمبر عام 2016 قرر البنك المركزى المصرى التعويم الثانى للجنيه ، حيث تم تحرير سعر صرف الجنيه امام العملات

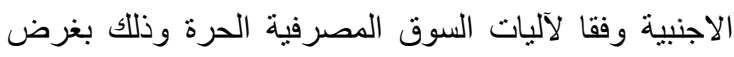

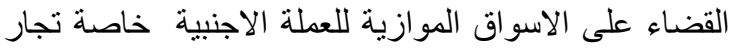

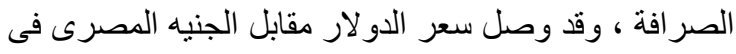
الربع الاول من عام 2017 الى 18.14 جنيه ، بينما كان قبل لتوليه

$$
\text { التعويم } 8 \text { جنيهات }
$$

وقد كان اول تعويم للجنيه المصرى فى يناير عام 2003 ،

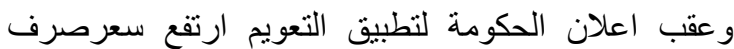
الدولار مقابل الجنيه المصرى من 3.70 الى 5.35 جنيهات للادو لار الواحد. (9) ومن المعروف اقتصاديا انه قد يؤثر سعر الصرف علي

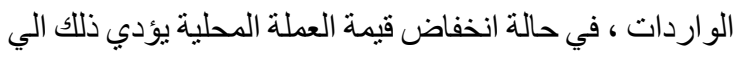

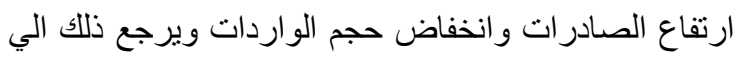
انخفاض اسعار السلع المحلية وزيادة المعروض النقدي و انخفاض الطلب علي السلع الأجنبية. اما في حالة ارتفاع قيمة العملة المحلية نتيحة لزيادة الصادرات التالئ وارتفاع الطلب علي السلع المحلية ،ينخفض المعروض النقدي في الداخل نتيجة لزياده الطلب علي السلع المحلية وترتفع الاسعار المحلية مما يؤدي ذلك الي زيادة حجم الواردات و هذا

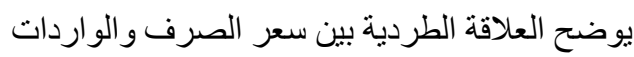
تأثير صدمة : تحرير سعر الصرف على الصادرات والواردات ناثر الاقتصاد المصرى خاصة قطاع التجارة الخارجية نتيجة تعويم الجنية المصرى وما نتج عن تغير سعر الصرف على الصى قيمة الصادرات والواردات , وكان هذا واضحا فى نأثر 2017/2016 الصادرات و الواردات فى السنة المالية ومابعدها عن الفتره السابقة للتعويم فى السنة المالية $.2016 / 2015$ الأثر على الصادرات ما قبل وبعد تحرير سعر الصرف: يتضح من الجدول رقم (1 ) ان قيمة الصادرات المصرية فى
التأثير على الواردات ما قبل وبعد احداث 25 يناير 2011 : يتضح من الجدول رقم ( 1 ) ان قيمة الواردات المصرية فى السنة المالية 2010/2009 قبل احداث ثورة 25 يناير ، بلغت

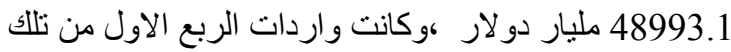
السنة المالية 11644.3 مليون دولار، والربع الثانى 11801.6 مليون دولار والربع الثالث 12058.2 مليون

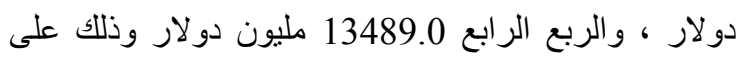

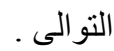
بينما فى السنة المالية 2011/2010 وذلك اثناء احداث ثورة 25 يناير , بلغت قيمة الواردات 54095.5 مليار دولار , وكانت واردات الربع الاول من تللك السنة المالية 13235.7

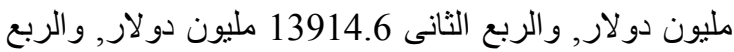
الثالث 12434.4 مليون دولار , و الربع الرابع 14510.8

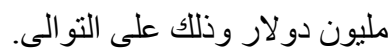

ومن خلال تحليل الواردات الدصرية قبل الازمة وبعد الازمة للجدول رقمى (2,3) يتبين هناك ارتفاع فى واردات السنة المالية 2011/2010 وهى السنة المالية للازمة المالية بمقدار 10.4 عن السنة المالية 2010/2009 , ونلاحظ ارتفاع ملحوظ للشهور الفصلية فى المقارنة بين تلك السنوات وكانت الفتره من اكتوبر الى ديسمبر 2010 الاكثر ارتفاعا للواردات بنسبة 17.9\% عن نفس الفتره للعام السابق للاحداث.

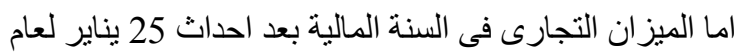
2010 /2011 فقد تبين بالجدول رقم (2) انه زاد العجز بنسبة \% \% عن السنة المالية 2010/2009 قبل الاحداث نظرا لزيادة الواردات , وكانت نسبة زيادة اجمالى الناتج المحلى الماحلى لعناصر الانتاج 7.5\% فقطو هى نسبة اقل من السنوات السابقة نظرا لتوقف الانتاج والنقل الداخلى لفترة الاحداث وظلت

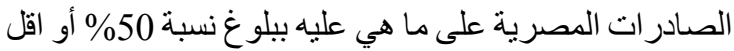

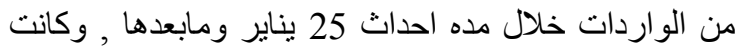
نسبة الصادرات الى اجمالى الناتج المحلى لعناصر الانفاق

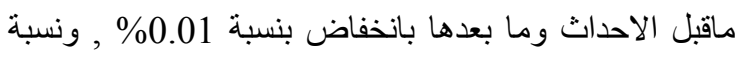
تغير الواردات الى الناتج المحلى المحلى قبل الاحداث وبعدها باتها

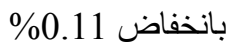


دولار ، و الربع الرابع 13489.0 مليون دولار وذللك على

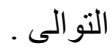
بينما فى السنة المالية 2016/2015 وذلك بعد تحرير سعر

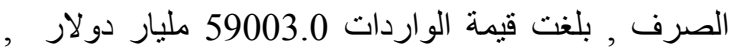
وكانت واردات الربع الاول من تللك السنة المالية 14700.4 مليون دولار، و الربع الثانى 15250.7 مليون دولار، و الربع الثالث 14555.3 مليون دولار ، والربع الرابع 14496.6 مليون دو لار وذللك على التو الى.

ومن خلال جدول (2,3) لتحليل الواردات المصرية قبل الازمة صدمة تحرير سعر الصرف وبعدها يتبين هنالك زيادة فى جي و اردات السنة المالية 2017/2016 و هى السنة المالية للصدمة بمقدار 2.8\% عن السنة المالية 2016/2015 , ونلاحظ ايضا ارتفاع قليل للثهور الفصلية فى المقارنة بين تلك السنوات وكانت الفترة من شهر اكتوبر الى ديسمبر 2017 هى اكثر الفترات ارتفعت فيها الواردات عن نفس الفترة من العام السابق

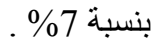

اما الميزان التجارى فى السنة المالية بعد صدمة تحرير سعر الصرف لعام 2016 /2017 فقد انخفض العجز بنسبة 3.9\% عن السنة المالية 2016/2015 قبل تحرير سعر الصرف نظر ا لزيادة الصادرات , وكانت نسبة اجمالى الناتج المحلى وفقا لعناصر الانفاق اقل بنسبة 25.2\% عن السنة المالية ما قبل الصدمة 2016/2015 نظرا لفروق سعر الصرف وارتفاع سعر الدولار امام الجنيه المصرى, وكانت نسبة الصادر ات الى اجمالى الناتج المحلى ماقبل الصدمة وما بعدها بزيادة 0.23\% , ونسبة تغير الواردات الى الناتج المحلى المحلى قبل الاحداث وبعدها بانخفاض 0.48\% (جدول 4) ويلاحظ وجود علاقة عكسية بين انخفاض سعر الصرف للجنيه المصري وزيادة الصادرات حيث تخفيض القيمة الخارجية للعملة المحلية يؤدي إلى ارتفاع أسعار الواردات المقومة بالعملة المحلية، ما يؤدي إلى انخفاض الطلب المحلي على بلى الواردات، وبالتالي انخفاض كمية وقيمة الواردات وذلك مع تو افر شرط أن تكون مرونة الطلب المحلي على الواردات أكبر من الصفر وبالتالي القضاء على فائض الطلب على العملة الأجنبية (11) و على عكس العلاقة الطبيعية بين الواردات وسعر الصرف
السنة المالية 2016/2015 قبل تحرير سعر الصرف, بلغت 18704.6 مليار دو لار , وكانت صادر ات الربع الاول من تلك السنة المالية 4731.1 مليون دولار,و الربع الثانى 4399.1 مليون دولار, والربع الثالث 4275.5 مليون دولار , و الربع الر ابع 5298.9 مليون دولار وذللك على التوالى .

بينما فى السنة المالية 2017/2016 وذلك بعد تحرير سعر الصرف , بلغت قيمة الصادرات 21728.2 مليار دولار , ركار وكانت صادرات الربع الاول من تلك السنة المالية 5261.4 مليون دولار, و الربع الثانى 5182.5 مليون دولار, و الربع

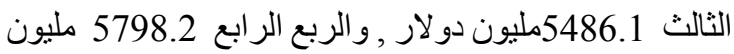
دو لار وذلك على التو الى. ومن خلال تحليل الصادر ات المصرية قبل صدمة تحرير سعر الصرف وما بعدها , يتبين هناك زيادة فى صادرات السنة المالية 2017/2016 وهى السنة المالية لما بعد صدمة تحرير سعر الصرف بمقدار 16.2\% عن السنة المالية ما قبل الاحداث 2016/2015 , ونلاحظ ارتفاع ملحوظ ايضا للشهور الفصلية قبل تحرير سعر الصرف ومابعدها فى المقارنة بين تلك السنوات ، وكانت الفترة من يناير الى مارس 2017 اكثر

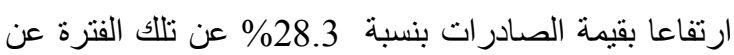
العام السابق ، حيث زاد سعر الصرف الاجنبى من 7.944جنيه/دولار فى العام 2016/2015 الى 17.694 جنيه/دو لار فى عام 2017/2016 بنسبة زيادة 122.7\% ويرجع تخفيض القيمة الخارجية للعملة المحلية انه يترتب عليه انخفاض أسعار الصادر ات مقومة بالعملة الأجنبية، وبالتالي زيادة الطلب الأجنبي على الصادرات، ما يؤدي إلى زيادة حجم الصـادرات بشرط أن تكون مرونة الطلب الأجنبي على الصـادرات أكبر من الواحد، وهذا بدوره ينعكس على زيادة عرض العملة الأجنبية الذي يؤدي إلى القضاء على فائض (10). الطلب على العملة الأجنبية

الأثر على الواردات ما قبل وبعد تحرير سعر الصرف : وفى الجدول (1) تشير قيمة الواردات المصرية فى السنة المالية 2016/2015 قبل صدمة تحرير سعر الصرف بمبلغ قدره 57387.7 مليار دولار ، وكانت واردات الربع الاول من تلك السنة المالية 11644.3 مليون دولار, والربع الثانى 11801.6 مليون دولار, والربع الثالث 12058.2 مليون 
الاتجاهين , فعلى صعيد التصدير , تواجه حركة الصادرات

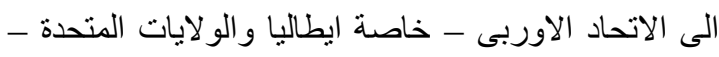

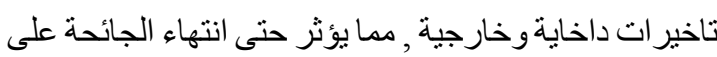

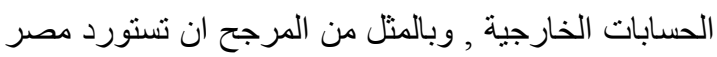
كميات أقل , حيث يركز الموردون بالخارج على الاسواق المحلية ,مما سيؤثر على عدد من الثركات المصنعة فى مصر

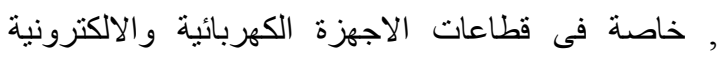
و المنسوجات التى تعتمد بشكل كبير على مستلزمات الانتاج

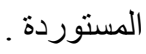

ويعتبر الثركاء التجاريين الرئيسيين لهصر وهم الصين

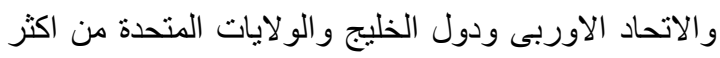
الاقتصادات التى تاثرت بأزمة كورونا , وفى محاولتهم

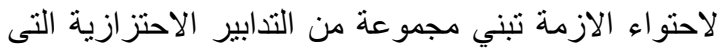

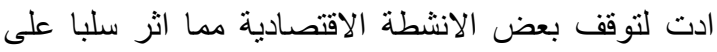

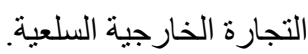

\section{اولا: الاثر على حركة الصادرات :}

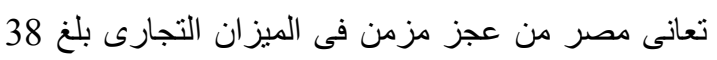

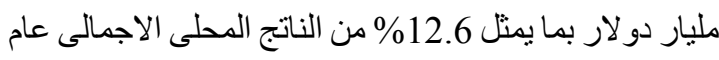
2018 / 2019 وقد يستمر العجز ايضا خلال عام 2021 اذا استمرت تداعيات ازمة كورونا للشهور الاولى من العام الجديد خاصة ان معظم الدول المنضررة صحيا من ازمة

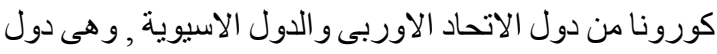
تستحوز على نسبة عالية من الصادرات المصرية, حيث

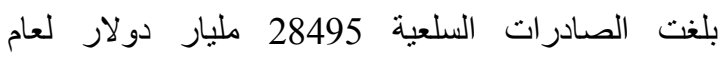
2019/2018 ويستحوز الاتحاد الاوربى على 42\% منها

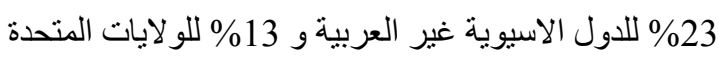

$$
\text { و 9.4\% للسعودية.(14 ) }
$$

وبالجدول رقم (1) يبين انه كانت صادر ات الربع الاول من تلك السنة المالية 6785.2 مليون دو لار, و الربع الثانى 7488.7 مليون دولار, و الربع الثالث 6638.1 مليون دولار , و الربع

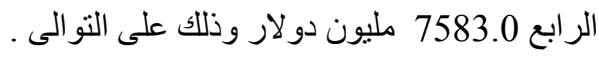

بينما فى السنة المالية 2020/2019 اثناء ازمة تداعيات

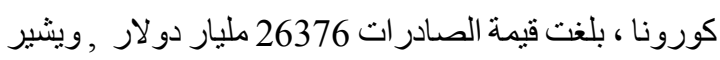
ذلك الى انخفاض الصادر ات المصرية فى العام المالى لجائحة
الجنيه المصري, نجد زيادة الواردات بنسبة 2.8\% عن ما قبل الصدمة قد يرجع ذلك إلي عوامل أخري تؤثر علي الواردات بخلاف سعر الصرف قد تكون زيادة الطلب على واردات

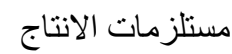

المحور الثالث : تداعيات تأثير جائحة كورونا على الميزان

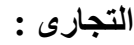
اشار تقرير لمؤتمر الامم المتحدة للتجارة والتتمية (اونكتاد)

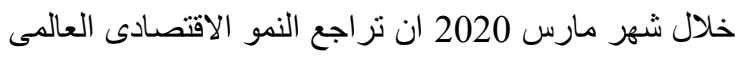

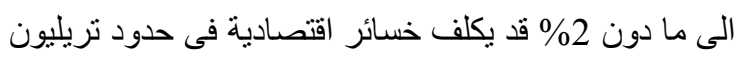
دو لار ستتحمل تبعاتها جميع دول العالم بدرجات متفاوتة . كما انه من المنوقع اذا استمرت الجائحة الى نهاية عام 2021 فأنه يؤدى الى ازدياد تباطؤ النمو الاقتصادى العالمى وتعطل

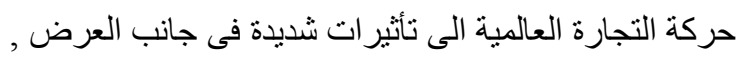
وحيث تعنمد مصر كغيرها من الدول النامية على مدخلات الانتاج و المو اد الخام المستوردة ,مما ينعكس سلبا على معدلات الانتاج ومستويات التوظيف وبالتالى على اختلال الميزان

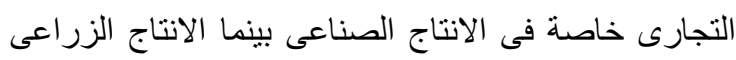
يتأثر قلبلا حيث اعتماده اقل على مدخلات الانتاج و المو اد الخام

المستوردة. (12) وقد ادى انتشار فيروس كورونا الى اضطر اب حركة التجارة

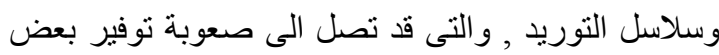
مكونات وقطع الغيار, وقد يواجه الموردون صعوبات فى لى لقالى التوريد. ومن المنوقع أن يؤدى تباطؤ الطلب العالمى الى ولى انخفاض اخر فى الصادرات المصرية اذا استمرت الجائحة حتى عام 2021 , كما ان اجراءات الحظر وارتباك سلاسل

الامداد العالمية ستحد من الواردات 2021 . (13)

والثير ازمة تلارداتيات فيروس كورونا على الصادرات

اشار تقرير غرفة التجارة الامريكية بالقاهرة ان اكبر الثركاء التجاريين الاتحاد الاوربى وايطاليا والسعودية والولايات

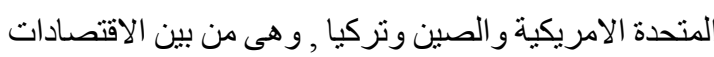

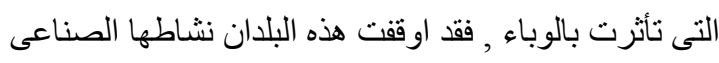

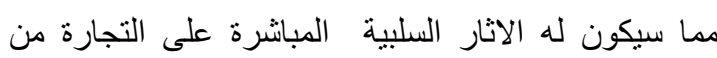


الوسيطة ومواد خام خاصة للصناعات الـندسية وصناعة النسيج فضلا ان مصر استوردت فى السنو ات الخمس الاخيرة نحو 40\% من احتباجاتها من المواد الغذائية. وحيث أن هيكل الواردات المصرية يتسم بعدم المرونة نظرا لمعظمه سلع اساسية من غذاء وبترول ومستلزمات انتاج مما لاشك فيه أنه سيترتب على انخفاض الواردات وعجز فى مستلزمات الانتاج لصناعات متعددة منها الالكترونات

$$
\text { و الملابس الجاهزة .(15) ) }
$$

و قد ساهمت هذه المؤشر ات فى انخفاض عجز الميزان التجاري الذى سجل 36465.1 مليار دولار خلال الفترة للسنة المالية 2020/2019 مقابل 38034.4 مليار دولار في نفس الفترة من العام المالي الماضي. وبلغت نسبة انخفاض الجز الى 4.1 مقارنة مع الفترة نفسها قبل عام ، نتيجة نتيجة انخفاض

$$
\text { المدفو عات عن الواردات فى ظل جائحة كورونا. }
$$

وتشير نسبة عجز الميزان التجارى الى اجمالى الناتج المحلى اثناء ازمة كورونا فى عام 2020/2019 يساوى 10.1 \% بينما كانت النسبة 12.6\% قبل الازمة فى السنة المالية $20019 / 2018$

\section{ثالثا: الاثز على الاقتصساد المصرى :}

اوضحت وكالة Mood's للتصنيف الايتمانى فى تقرير لها فى بداية عام 2020 أن الصدمة النى سبيتها تداعيات ازمة فيروس كورونا بالنسبة للاقتصاد المصرى , اثرث على زيادة العجز فى ميز ان المدفو عات وتتمثل بثكل رئيسي فى الضغط على متطلبات التمويل الخارجى , و ايضا فى انخفاض عائدات السياحة وتحويلات العاملين بالخارج , وتباطؤ معدلات النمو الاقتصادى , و انه من المتوقع حدوث ارتفاع مؤقت فى عجز الحساب الجارى بصل الى 5.4\% من الناتج المحلى الاجمالى عام 2020 , وأن تتراوح الفجوله التمويلية بين 12 و 13 مليار

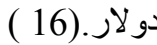
كما أنه قد تثتأثر مصادر النق الاجنبى حال استمر اره حتى نهاية

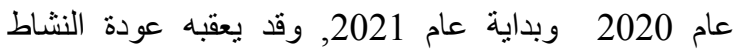
الاقتصادى تذريجيا بكامل طاقتة الاقتصادية خاصة بعد تخفيف الاجراءات الاحتزازية وبدء استخدام لقاح فيروس كورونا , و هو مايعنى ارتفاع الالتز امات الخار جية خاصة على مستوى

الو اردات وبالاخص مستلزمات الانتاج.(17) و قد اظهرث المؤشرات الاولية لموازنة العام المالى
كورونا للعام المالى 2020/2019 بنسبة 7.4\% بالمقارنة

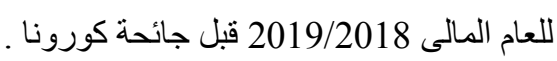
وكانت صادرات الربع الاول من تلك السنة المالية 7120.8 مليون دو لار, و الربع الثانى 7130.2 مليون دو لار, و الربع الثالث 6702.6 مليون دولار , و الربع الرابع 5422.4 مليون دولار وذلك على التوالى , ويشير ذلك الى انخفاض متو الى مع اثتنداد ازمة الجائحة.

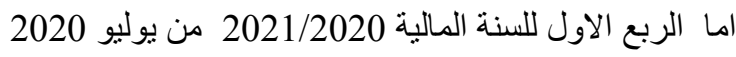
الى سبتمبر 2020 شهدت الصادر ات انخفاضا مع دخول مصر ذروة جائحة كورونا بلغت قيمته 6395 مليار دو لار بانخفاض لفاضل

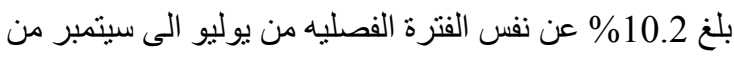

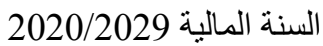
ثنانيا: الاثر على حركة الواردات : يشير الجدول رقم (1) ان الواردات بلغت لعام

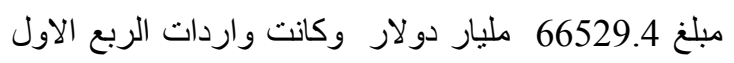

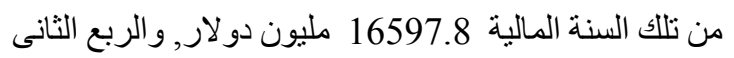
16927.6 مليون دولار, و الربع الثالث 17133.5 مليون دولار , و الربع الرابع 15870.5 مليون دولار وذللك على

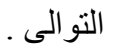

بينما فى السنة المالية 2020/2019 وذلك اثناء ازمة تداعيات

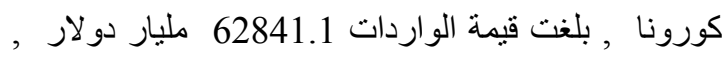
وكانت وارداتت الربع الاول من تلك السنة المالية 15904.0

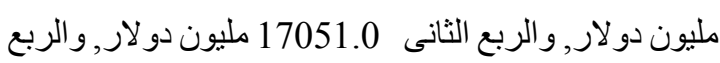
الثالث 16057.1 مليون دولار ,و الربع الرابع 13829.0 مليون دولار وذللك على التوالى، ويشير التى انخفاض الواردات بنحو5.6\% خلال 2019/2018 اما الربع الاول للسنة المالية 2021/2020 من يوليو 2020 الى سبتمبر 2020 شهدت الواردات انخفاضا بلغت قيمته 13398 مليار دولار بانخفاض بلغ 15.8\% عن نفس الفترة الفصليه من يوليو الى سيتمبر من السنة المالية 2020/2029 وقد كانت نسب واردات السلع منها 34\% تأتى من الاتحاد الاوربى بينما 19\% من الواردات المصرية جاءت من الصين و8.4\% من الو لايات المتحدة الامريكية. وكانت الواردات المصرية اغلبها مستلزمات مواداد الانتاج 


\section{لقطاع التجارة الخارجية المصري :}

قامت الحكومة المصرية عقب تفثى جائحة كورونا بإقرار حزمة من الاجر اءات الاستباقية سو اء كانت اقتصادية أو مالية أواجتماعية , وذللك بمبلغ 100 مليار جنيه لتمويل الخطة الثاملة؛ التي تعد بمثابة حائط صد قوي لمجابهة آثار فيروس كورونا، ومساندة القطاعات الانتاجية الاقتصادية وقد قامت وزارة التجارة و الصناعة بتنفيذ اجر اءات تحفيزية لمساندة وتنشيط قطاع الصادر ات وواردات مستلزمات الانتاج

و المواد الخام للمشروعات الانتاجية فيما يأتى : (22) اولا: الاجراءات التحفيزية لقطاع التجارة الخارجية

(الصادر ات و الواردات )

- تكليف جهاز التمثيل التجارى بالخار بتحقيق مزيد من التواصل بين المنتجين و المصدرين المصريين فى ظل توقف رحلات الطيران فى العديد من دول العالم , وذللك للحفاظ على التواجد المصرى بالاسو اق الخارجية. فتح خطوط شحن برية جديد مع الدول العربية و الافريقية لتفادى توقف حركة النقل الجوى لبعض

الدول

تأجيل سداد الاقساط الضريبية المستحقة على شركات التصدير والاستير اد و المصانع لفترة محددة

$$
\text { وبدون فوائد }
$$

تخفيض اسعار الشحن الجوى لشركة مصر للطبر ان خاصة للدول العربية. مساعدة المصانع و الشركات المصدرة من خلال صندوق دعم تنمية الصادر ات تنشيط الاتفاقات الدولية فى تحقيق اهداف التصدير لتلاشى تعسف بعض الدول فى قبول المنتجات المصرية ومطابقتها للمو اصفات القياسية المبالغة مساندة الحكومة بالدعم المادى واللوجستى للقطاع التصديرى خاصة الصادر ات الاوربية - - التواصل مع كافة المصانع للتأكد من توافر مستلزمات الانتاج وبصفة خاصة المسنوردة منها لضمان استمر ار عمليات التشغيل و عدم توقف حركة الانتاج، وكذا متابعة انتظام سلاسل التوريد بين كافة

حلقات الصناعة
2021/2020 و السيناريوهات التى أعدتها وزارة التخطيط و التتمية الاقتصادية , بشأن مدى تأثير أزمة كوروناخدلال الفترة المقبلة , واثبتت وجود انعكاسات سلبية على اغلب تللك المؤشرات , حيث أن معدل النمو الاقتصادى الذى كان المستهدف تحقيقة بنهاية العام 2020 ( اى نهاية شهر يونيو) يصل الى 6\% لكن وبسبب الازمة الحالية , دن المتوقع أن يصل الى نحو 4.5\% كما أن الازمة ستؤثر على معدل نمو الاقتصاد فى السنة المالية المقبلة , الذى يبدأ فى يوليو 2020 وينتهى فى يونيو 2021 , حيث من المتوقع تحقيق معدل نمو اقتصادى 4.5\% وكذلك من المتوقع أن يرتفع التضخم فى بداية

\% \% نتيجة للطلب الز ائد على بعض المنتجات ومحدودية زيادة الطاقة الانتاجية فى الاجل القصير , فضلا عن صعوبة احلال مستلزمات الانتاج من الواردات.(18 ) وفى تقرير للبنك الدولى عن تراجع تحويلات العاملين المصريين بالخارج بنسبة 21.5\% خلال عام 2020 مقارنة بنمو بلغت نسبته 5\% عام 2019 (19) و اشار تقرير غرفة التجارة الامريكية بالقاهرة ان تلك الازمة ضربت التجارة العالمية حتى تشهر ممرات التجارة الدولية بالفعل انخفاضات ملحوظة فى حركة المرور و الاير ادات , لذا من المتوقع أن تشهد قناة السويس بعض التراجعات , حيث انه فى شهر فبر اير 2020 , انخفض عدد سفن الحاويات المارة عبر القناة بنسبة 7.3\% فى حين تراجع عدد سفن الركاب و البضائع بنسبة 22.2\% و 1.3\% على التوالى, مما يؤدى لانخفاض الرسوم المدفو عة بالعملة الاجنبية بمصر, اضافة الى عجز الحساب الجارى والتأثير سلبا على سعر صرف الجنية

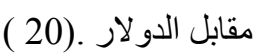
اما اثر تداعيات فيروس كورونا على الاحتياطى النقدى خلال شهرى مارس وابريل 2020 بنحو 8.5 مليار دولار , وذلك بعد خروج نحو 15 مليار دولار من استثمار ات الاجانب فى Mood's ادوات الدين الحكومى بحسب تقديرات وكالة للتصنيف الائتمانى , و اعنبرت ان مستوى الاحتياطيات الدولية فى وضع جيد يسمح بالتغلب على هذه التدفقات الخارجة على المدى القصير , وسيقابل انخفاض الطلب المتوقع على الواردات فى الفترة القادمة.( 21) المحور الرابع : الاجراعات التحفيزية والاصلاحات الهيكلية 
العالمية واذواق المستهلك الاجنبى تجاه المنتجات

$$
\text { المصرية وفتح اسواق جديدة لها. }
$$

- ت تمية الصادرات والانتقال من سياسة تصدير

الفائض من الاستههلاك المحلى الى الانتاج من اجل

التصدير, , والاحلال محل الواردات فى السلع

و الخدمات

- مواجهه معوقات الصادرات والواردات وتعديل

قانون الجمارك لترشيد تكاليفها وتبسيط الاجراءات

وتفعيل النافذه الو احدة

- العمل على تطوير سياسات دعم الصادرات ,

وتسوية مطالبات المصدرين , وتفيل تنشيط دور

$$
\text { التمثيل التجارى }
$$

- توجية الانشطة الاستثمارية فى مصر نحو الانشطة

الصناعية والزر اعية بدلا من تركز ها فى الانثطة

$$
\text { العقارية و الاستخر اجية }
$$

الاستثتاجات : - الات

من خلال تحليل الباحث برصد قيم حركة الواردات و الصادر ات للميزان التجارى المصرى للازمات العالمية والمحلية من الفترة 2007 الى الفترة الحالية 2020 وفى ظل تداعيات ازمة كورونا , ومع الاجراءات التى اتخذتها الحكومة المصرية

$$
\text { نستتنج ما بلى : }
$$

1. اثرت جائحة كورونا على النمو الاقتصادى

المصرى حيث كان المستهدف 6\% ولكن بسبب تأثثر الازمة من المتوقع ان يصل الى 4.5\% فى نهاية 2020

2. - انخفضت الصادرات فى عام تداعيات ازمة

كورونا 2020/2019 بنسبة 7.4\% عن عام ما قبل

كورونا 2019/2018 حتى فى الربع الاول من السنة المالية 2021/2020 حدث انخفاضا قدرة 10.2 \% عن نفس الفترة 2020/2019 و هذا يحقق الفرض الاول فى التأثير جائحة كورونا فى انخفاض الصادرات مما بعنى ان التأثير سلبى على زيادة

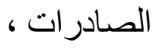
3. انخففضت الواردات بنحو5.6\% خلال عام تداعيات ازمة كورونا 2019 2020 بالمقارنة لعام 2019/2018 , وكذلك حدث انخفاض فى الفترة من بن بهرد يوليو 2020 الى سبتمبر 2020 بلغت قيمته
- تخفيض سعر الغاز الطبيعي للصناعة الي حوالي

4.5 دولار وخفض اسعار الكهرباء للصناعة بحو الي 10 قروش قيام البنك المركزي المصرى بصدور قرارات تصالح البنوك مع المتعثرين في سداد قروضهم وتأجيل استحقاقات الاقساط وتيسير اجراءات الخدمات المصرفية للمصدرين واصحاب

$$
\text { المشرو عات. }
$$

- خفض اسعار العائد لدي البنك المركزي بحوالي 3\%مع اتاحة الحدود الائتمانية لتمويل رأس مال وبالأخص صرف رو اتب العاملين بالثركات. وقدر حذر البنك الدولى ومنظمة التجارة العالمية ان الازمة الحالية قد تؤدى الى تداعيات تفوق فى شدتها أى ازمات الى تداعيات تفوق فى شدتها أى أزمات سابقة مرت به و العالم . و ان احد هذه التداعيات الهامة هو الدخول فى ركود اقتصادى عالمى وما يتبع من نر اجع فى معدل النمو الاقتصادى العالمى ولكافة الاقاليم ومنها مصر. لذلك اثرت الازمة سلبا على العديد من المتغيرات وقطاعات الاقتصاد المصرى , لذا كان لز اما على الدولة بالقيام بتلك الحزم التحفيزية و اتباع سياسات علاجية للحد من تراجع النمو , ولتحفيز النشاط الاقتصادى , وحماية العمالة غير المنتظمة وكلها اجراءات هامة ومطلوبة فى ظل ارتفاع عدم اليقين المصاحب للازمة وارتفاع سعر الفائدة . ثانيا : الاصلاحات الهيكلية لاختلال الميزان التجارى : ويرى الباحث ان ازمة تداعيات جائحة كورونا ليست الازمة الاولى فى الاقتصاد المصرى ولن تكون الاخيرة , ولذا يجب ان تتدارك هذه الازمات فى اصلاحات هيكلية للاقتصاد المصرى فى ضوء تللك الازمة الاخيرة , وبالتركيز على الاصلاحات الخاصة لمعالجة العجز المزمن فى الميزان التجارى المصرى. - الت ويقترح الباحث تلك البنود التالية لمعالجة اختلالات الميزان

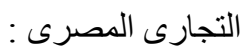

- تغيير التركيب السلعى للصادرات و الواردات بحيث

يساعد ذلك على رفع كفاءة التجارة الخارجية. - - تغيير التوزيع الجغرافى للتجارة الخارجية من صادرات وواردات فى ضوء دراسة الاسواق 
بنسبة اكبر من 122\% عما قبل تحرير سعر

الصرف و هذا بحقق ايضا الفرض الثالث.

التوصيات : - الت الت

1. ضرورة انثاء ادارة عامة للازمات فى كل وزارة

تضم خبر اء ومختصين فى الشان الموكل لهم بادارة

ضرورة هيكلة الاقتصاد المصرى الانتاجى وازالة التشوهات لمنع العجز في ميزان التجارى. 3. ينبغي علي الدولة أن تزيد من المشرو عات الصغيرة ،وتوفر فرص عمل للثباب حتى تزيد من الإتناج فتقلل نسبة الو اردات من الخارج. 4. التوسع في عقد الاتفاقيات وتوقيع العقود التصديرية طويلة الأجل بين مصر و العالم الخارجي؛ وصولا إلى تحقي الاستقرار و الثبات في الدخل الناتج عن لين

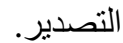
5. الاهتمام بالنقل البرى ونقل السكك الحديدية مع الدول

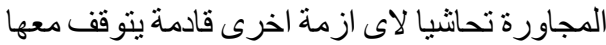

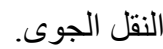
6. التركيز على السلع التى حققت مصر فيها ميزة تنافسية بحيث يتم تشجعيها بمزيد من المعاملة

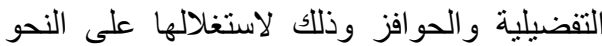

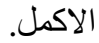
7. تطوير البنية التحتية بما يتفق مع منطلبات التصدير بما فى ذلك النقل و الثحن و الاتصالات و الكهرباء خاصة الاستثمار فى تحسين خدمات

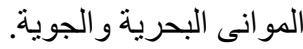
8. ضرورة تضافر الجهود بين الحكومة والقطاع التهريه الخاص و والمؤسسات التعليمية و والبحثية والهتمع المدنى للتغلب على المعوقات التى ولى تحول دون تحقيق قفزة نوعية وكمية فى

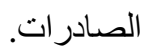

13398 مليار دولار بانخفاض بلغ 15.8\% عن نفس الفترة الفصليه من يوليو الى سيتمبر من السنة المالية 2020/2029 , و هذا يحقق الفرض الثانى تاثير جائحة كورونا تأثير ايجابى فى خفض الواردات ، يأتي على قائمة شركاء مصر التجاريين

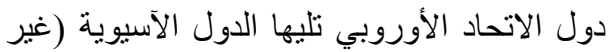

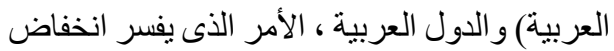
حجم الواردات المصرية بشكل واضح، حيث تعد تلاك الدول هي أكثر الدول تأثرا بالأزمة الراهنة،

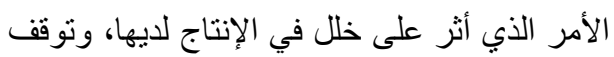
في حركة الموانئ و الطائرات، وبالتالي التأثير على التى وني حركة التجارة الخارجية لديها.

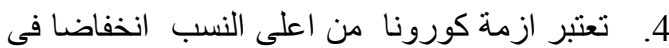
عجز الميزان التجارى بالنسبة للازمات الاخرى التى تناولها الباحث حيث انخفض العجز بنسبة 4.1 بيتما كانت صدمة تحرير سعر الصرف انخفض العجز الى 3.9 \% فقط ، بعكس الازمة المالية العالمبة واحداث 25 يناير اللتان ارتفعا فيهما عجز الميزان التجارى الى 7.5\% ، 7.9\% و وذا يحقق الفرض الثالث ويرجع انخفاض عجز الموازنة فى تداعيات ازمة كورونا الى انخفاض الو اردات بنسبة 6.3\% 5. تعتبر نسبة عجز الميزان التجارى الى اجمالى الناتج

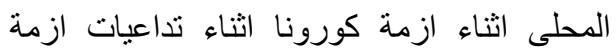
كورونا هى الاقل بالمقارنع مع الازمات الخارجية التهاء و الداخلية لمصر حيث كانت 10.1 \% وكانت الفرق الان بين عجز الميزان التجارى بالنسبة الى اجمالى الناتج المحلى ما قبل الازمة وما بعدها 2.5\% بينما كانت المارى

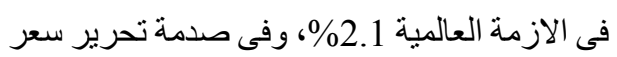
الصرف 3.3 \% ويرجع ذلك الى انخفاض اجمالى الناتج المحلى مقوما بسعر الدولار والذى ارتفع

جدول (1) تطور الصادرات والواردات المصرية من عام 2006/2005 الى عام 2020/2019

\begin{tabular}{|c|c|c|c|c|c|c|c|c|c|c|c|}
\hline \multirow[b]{2}{*}{ الميزان التجارى } & \multirow[b]{2}{*}{ الوارداتى } & \multicolumn{4}{|c|}{ الواردات } & \multirow[b]{2}{*}{ الصنادرات } & \multicolumn{4}{|c|}{ الصادرات } & \\
\hline & & Q1 & Q2 & Q3 & Q4 & & Q1 & Q2 & Q3 & Q4 & \\
\hline
\end{tabular}


Delta University Scientific Journal

Volume 4 Issue 1 April (2021)

\begin{tabular}{|c|c|c|c|c|c|c|c|c|c|c|c|}
\hline-11985.9 & 30441 & 7348.3 & 7246.3 & 7128.6 & 8717.8 & 18455.1 & 4031.0 & 4544.5 & 4884.9 & 4994.7 & $2005 / 2006$ \\
\hline-16290.6 & 8308.1 & 8551.1 & 8873.4 & 9211.1 & 11672.5 & 22017.5 & 5410.8 & 5255.2 & 5232.5 & 6119.0 & $2006 / 2007$ \\
\hline-23415.4 & 2771.2 & 11190.7 & 13181.3 & 13255.6 & 15143.6 & 29355.8 & 5989.8 & 7113.3 & 7734.7 & 8518.0 & $2007 / 2008$ \\
\hline-25173.3 & 50342.2 & 15162.9 & 13060.9 & 10523.6 & 11594.8 & 25168.9 & 8162.9 & 5433.4 & 5657.8 & 5914.8 & 009 \\
\hline-25120 & 48993.1 & 11644.3 & 11801.6 & & & & 5390.3 & 6126.4 & & & \\
\hline-27103 & 54095.5 & 13235.7 & 13914.6 & 12434.4 & 14510.8 & 26992.5 & 6102.0 & 6565.8 & 6243.3 & 8081.4 & \\
\hline-34130 & 59210.9 & 14715.7 & 14796.7 & 145 & 2.2 & & 4.8 & 3.9 & & & \\
\hline-30694.4 & 57682.5 & 13716.8 & 16411.7 & 13530.3 & & 38.1 & 6775.1 & 6833.5 & 9.9 & & \\
\hline-34159.3 & 60181.9 & 13807.8 & 14655.0 & 15535.9 & 83.2 & 22.6 & 6187.9 & 6910.4 & 6403.4 & 0.9 & 014 \\
\hline-39060.4 & & & & & & & & & & & \\
\hline-38683.1 & $\mathbf{5 7 3 8 7 . 7}$ & 14742.6 & 14265.9 & 14245.8 & 14133.4 & 18704.6 & 4731.1 & 4399.1 & 5.5 & 8.9 & 016 \\
\hline-37274.8 & & & & & & & & & & & \\
\hline-37276 & 63103.0 & 14747.6 & 16055.3 & 16011.4 & 16288.7 & 25827.0 & .45839 & 6215.7 & 6755.8 & 7016.1 & $2017 / 2018$ \\
\hline-38034.4 & 66529.4 & & 16927.6 & & & 28495.0 & & 7488.7 & 6638.1 & 7583.0 & $2018 / 2019$ \\
\hline \multirow[t]{2}{*}{-36465.1} & 62841.1 & 15904.0 & 17051.0 & 16057.1 & 13829.0 & 26376.0 & 7120.8 & 7130.2 & 6702.6 & 5422.4 & $2020 / 2019$ \\
\hline & & 13398.0 & & & & & 6395.0 & & & & $2021 / 2020$ \\
\hline
\end{tabular}

$$
\text { عمل الباحث مستعينا بارقام البنك المركزى لعدة سنوات }
$$

جدول (2) مقارنة الصادرات والواردات والميزان التجارى للازمات المصرية

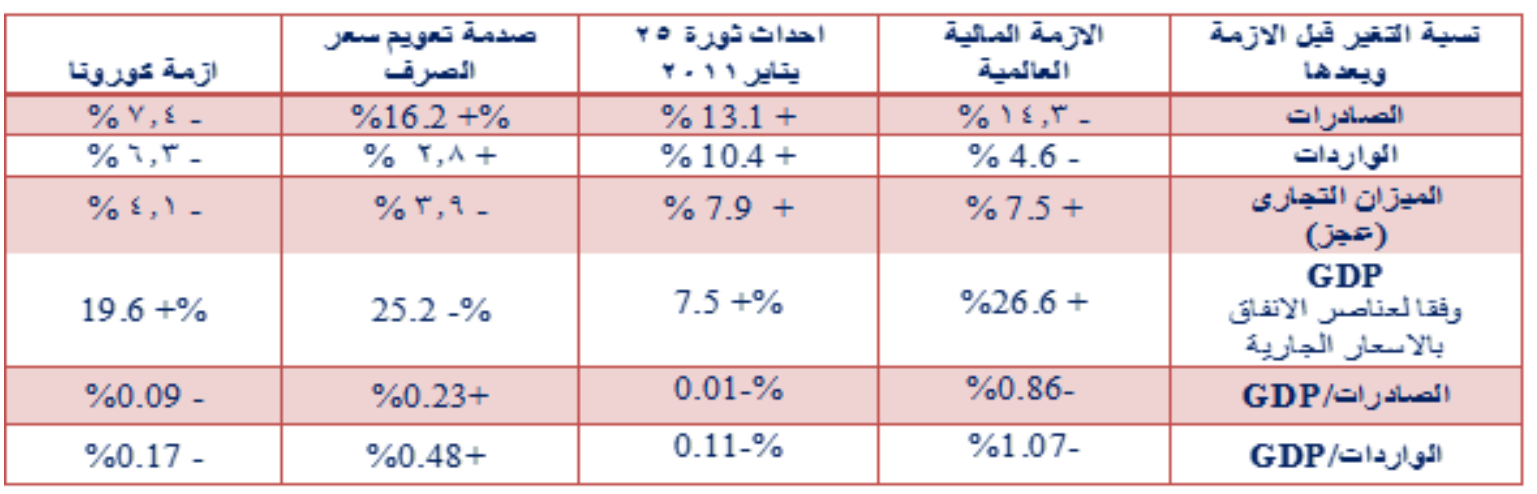

جدول (3) مقارنة الصادرات و الواردات والميزان التجارى قبل وبعد الازمات

\begin{tabular}{|c|c|c|c|c|c|c|c|c|}
\hline \multicolumn{2}{|c|}{ ازمة كورونا } & \multicolumn{2}{|c|}{ صدمة تحريز سعز الصرف } & \multicolumn{2}{|c|}{ ثورة 25 ينايز 2011} & \multicolumn{2}{|c|}{ الازمة المالية العالمية } & \\
\hline أثتاء الازمهة & قيل الازمة & بعد الصدمة & قيل الصدمة & بعد الازمة & قيل الازمة & بعد الازمة & قيل الازمـة & \\
\hline $2019 / 2020$ & 2018/2019 & $2016 / 2017$ & $2015 / 2016$ & $2010 / 2011$ & $2009 / 2010$ & $2008 / 2009$ & $2007 / 2008$ & \\
\hline 26376.0 & 28495.0 & 21728.2 & 18704.6 & 26992.5 & 23873.1 & 25168.9 & 29355.8 & الصسادرات \\
\hline 62841.1 & 66529.4 & 59003.0 & 57387.7 & 54095.5 & 48993.1 & 50342.2 & 52771.2 & الو ارداث \\
\hline-36465.1 & -38034.4 & -37274.8 & -38683.1 & -27103 & -25120 & -25173.3 & -23415.4 & التجيزان \\
\hline 360.23 & 301.08 & 252.01 & 336.84 & 235.24 & 218.82 & 206.97 & 163.52 & $\begin{array}{c}\text { GDP } \\
(\$)\end{array}$ \\
\hline$\% 10.1$ & $\% 12.6$ & 14.8 & $\% 11.5$ & $\% 11.5$ & $\% 11.5$ & $\% 12.2$ & $\% 14.3$ & 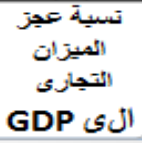 \\
\hline
\end{tabular}

رسم بيانى الصادرات والواردات المصرية من عام 2006/2005 الى عام 2020/2029 
Delta University Scientific Journal

Volume 4 Issue 1 April (2021)

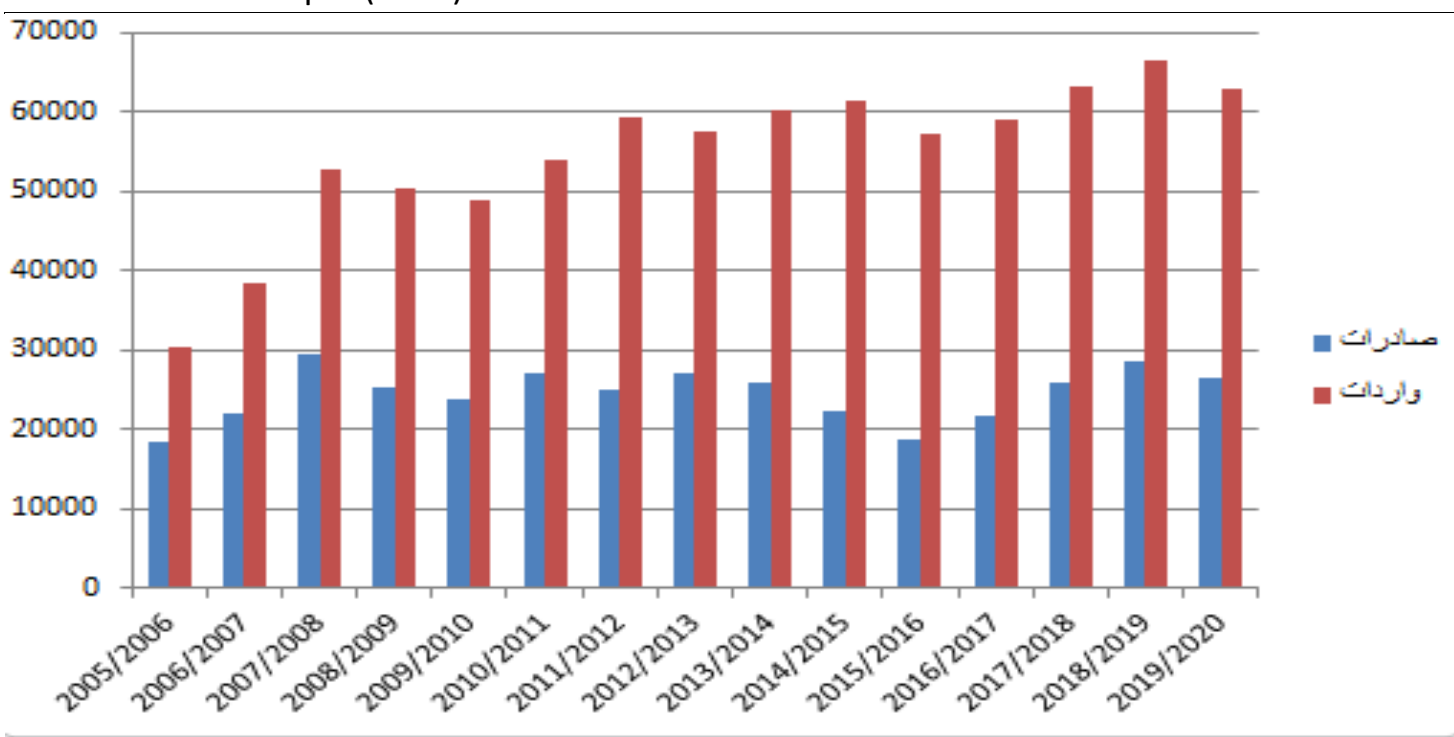

جدول (4) متوسط سعر الصرف الرسمى الفصلى من عام 2006/2005 حتى عام 2020/2019

\begin{tabular}{|c|c|c|c|c|c|c|c|}
\hline \multicolumn{2}{|c|}{ متوسط سعر الصرف الرسمى } & & \multirow{2}{*}{ السنوات } & \multicolumn{2}{|c|}{ متوسط سعر الصرف الرسمى } & & \multirow{2}{*}{ السنوات } \\
\hline بيع & شراء - اء & & & بيع & شراء & & \\
\hline 6.964 & 6.945 & Q1 & \multirow{4}{*}{$2014 / 2013$} & 5.778 & 5.758 & Q1 & \multirow{4}{*}{$2006 / 2005$} \\
\hline 6.895 & 6.875 & Q2 & & 5.762 & 5.742 & $\mathrm{Q} 2$ & \\
\hline 6.961 & 6.941 & Q3 & & 5.653 & 5.633 & Q3 & \\
\hline 7.077 & 7.057 & Q4 & & 5.768 & 5.748 & Q4 & \\
\hline 7.15 & 7.13 & Q1 & \multirow{4}{*}{$2015 / 2014$} & 5.747 & 5.727 & Q1 & \multirow{4}{*}{$2007 / 2006$} \\
\hline 7.15 & 7.13 & $\mathrm{Q} 2$ & & 5.732 & 5.712 & $\mathrm{Q} 2$ & \\
\hline 7.541 & 7.521 & Q3 & & 5.616 & 5.596 & Q3 & \\
\hline 7.541 & 7.521 & Q4 & & 5.702 & 5.682 & $\mathrm{Q} 4$ & \\
\hline 7.74 & 7.72 & Q1 & \multirow{4}{*}{$2016 / 2015$} & 5.578 & 5.558 & Q1 & \multirow{4}{*}{$2008 / 2007$} \\
\hline 7.798 & 7.778 & Q2 & & 5.536 & 5.516 & Q2 & \\
\hline 7.964 & 7.944 & Q3 & & 5.419 & 5.399 & Q3 & \\
\hline 8.79 & 8.77 & $\mathrm{Q} 4$ & & 5.382 & 5.364 & $\mathrm{Q} 4$ & \\
\hline 8.79 & 8.77 & Q1 & \multirow{4}{*}{$2017 / 2016$} & 5.375 & 5.355 & Q1 & \multirow{4}{*}{$2008 / 2009$} \\
\hline 14.675 & 14.374 & $\mathrm{Q} 2$ & & 5.548 & 5.528 & $\mathrm{Q} 2$ & \\
\hline 17.851 & 17.694 & $\mathrm{Q} 3$ & & 5.595 & 5.575 & Q3 & \\
\hline 18.144 & 18.018 & Q4 & & 5.629 & 5.609 & $\mathrm{Q} 4$ & \\
\hline 17.844 & 17.722 & Q1 & \multirow{4}{*}{$2018 / 2017$} & 5.466 & 5.446 & Q1 & \multirow{4}{*}{$2010 / 2009$} \\
\hline 17.758 & 17.644 & $\mathrm{Q} 2$ & & 5.485 & 5.465 & $\mathrm{Q} 2$ & \\
\hline 17.727 & 17.603 & Q3 & & 5.484 & 5.464 & Q3 & \\
\hline 17.861 & 17.732 & Q4 & & 5.622 & 5.602 & Q4 & \\
\hline 17.959 & 17.832 & Q1 & \multirow{4}{*}{$2019 / 2018$} & 5.708 & 5.688 & Q1 & \multirow{4}{*}{$2011 / 2010$} \\
\hline 17.974 & 17.854 & Q2 & & 5.771 & 5.751 & $\mathrm{Q} 2$ & \\
\hline 17.664 & 17.537 & Q3 & & 5.891 & 5.871 & Q3 & \\
\hline 17.082 & 16.955 & Q4 & & 5.961 & 5.941 & $\mathrm{Q} 4$ & \\
\hline 16.582 & 16.457 & Q1 & \multirow{4}{*}{$2020 / 2019$} & 5.972 & 5.952 & Q1 & \multirow{4}{*}{$2012 / 2011$} \\
\hline 16.206 & 16.082 & $\mathrm{Q} 2$ & & 6.001 & 5.981 & $\mathrm{Q} 2$ & \\
\hline 15.821 & 15.694 & Q3 & & 5.857 & 5.837 & Q3 & \\
\hline 15.978 & 15.848 & $\mathrm{Q} 4$ & & 6.068 & 6.048 & $\mathrm{Q} 4$ & \\
\hline 15.955 & 15.826 & Q1 & \multirow{4}{*}{$2021 / 2020$} & 5.09 & 5.07 & Q1 & \multirow{4}{*}{ 2013/2012 } \\
\hline 15752 & 15.623 & Q2 & & 6.134 & 6.114 & $\mathrm{Q} 2$ & \\
\hline & & Q3 & & 6.692 & 6.672 & Q3 & \\
\hline & & Q4 & & 6.948 & 6.928 & $\mathrm{Q} 4$ & \\
\hline
\end{tabular}

عمل الباحث مستعينا بارقام البنك المركزى لعدة سنوات فصلية

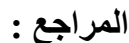


12. منظمة الامم المتحدة للتجارة والتمية (الاونكتاد)

https://unctad.org/en/pages/coronavirus.

aspx

13. معهد التخطبط القومى, سلسلة اور اق السياسات"

تداعيات كوروناو اثرها على العو ائد المصرية من

النقد الاجنبى" اصدار رقم 17, يونيو 2020

American Chamber of Commerce in .14

. Egypt,2020

http://www.amcham.org.eg

15. البنك المركزى المصرى,المجلة الاقتصادية , اعداد

https://www.cbe.org.eg متفرقة

16. وكالة موديز للتصنيف الائتمانى

http://www.moodys.com

17. معهد التخطبط القومى, سلسلة اور اق السياسات"

التداعيات المحتملة لازمة كورونا على الاقتصاد

المصرى " اصدار رقم 5, مايو 2020

18. هالة السعيد , سيناريو هات خطة التنمية للعام

(2021/2020), مجلة الاهر ام الاقتصادى

2020,القاهرة,

19. البنك الدولى , تقارير متعددة,

https://www.worldbank.com

American Chamber of Commerce in .20

. Egypt,2020

http://www.amcham.org.eg

21. وكالة موديز للتصنيف الائتمانى

http://www.moodys.com

22. مجلة صنع فى مصر- العدد19, وزارة التجارة

والصناعة المصرية, ابريل 2020
1. أحمد عبد الرحمن يسرى و آخرون،"الاقتصاد

الدولي"، كلية التجارة جامعة الإسكندرية، 2005

2. مريم عبد الواحد كثك "تخفيض سعر الصرف

و اثره على الميزان التجارى المصرى" المجلة

العلمية لقطاع كليات التجارة,جامعة الازهر ,العدد17

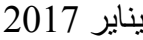

3. داود حسام على ، مبادئ الاقتصاد الكلي ، دار

المسيرة للنشر والتوزيع و الطباعة، عمان، الطبعة

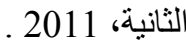

4. معهد التخطيط القومى, سلسلة اور اق السياسات"

تداعيات كورونا واثرها على العوائد المصرية من

النقد الاجنبى" اصدار رقم 17, يونيو 2020

5. الجهاز المركزى للتعبئة العامة والاحصاء

Www.capmas.org

6. فريد كورتل ، "در اسة الأزمة المالية العالمية وأثرها

على الاقتصاديات العربية" ، مجلة أبحاث روسيكادا

الدولية العلمية جامعة سكيكدة الجزائر , اكتوبر

2009

7. مجلة صنع فى مصر - العدد19, وزارة التجارة

و الصناعة المصرية, ابريل 2020

8. ماجدة قنديل ـ الاقتصاد المصري بعد ثورة 25 يناير

، الخدمات والافاق المستقبلية ، المركز المصري

للار اسات الاقتصادية, 2011

9. البنك المركزى المصرى,المجلة الاقتصادية , اعداد

https://www.cbe.org.eg منقرقة

10. محمد دياب ، "التجارة في عصر العولمة "، دار

المنهل اللبناني، لبنان، 2010

11. ماجد عبدالعظيم قابيل , "اثر تعويم الجنية المصرى

على اداء التجارة الخارجية " , مجلة مصر

المعاصرة,القاهرة 2017 